\title{
Complex refractive indices of Saharan dust samples at visible and near UV wavelengths: a laboratory study
}

\author{
R. Wagner ${ }^{1}$, T. Ajtai ${ }^{2}$, K. Kandler ${ }^{3}$, K. Lieke ${ }^{3}$, C. Linke ${ }^{1}$, T. Müller ${ }^{4}$, M. Schnaiter ${ }^{1}$, and M. Vragel ${ }^{1}$ \\ ${ }^{1}$ Karlsruhe Inst. of Technology, Inst. for Meteorology and Climate Research, P.O. Box 3640, 76021 Karlsruhe, Germany \\ ${ }^{2}$ University of Szeged, Department of Optics and Quantum Electronics, Dóm tér 9, 6720 Szeged, Hungary \\ ${ }^{3}$ Darmstadt University of Technology, Institute of Applied Geosciences, Schnittspahnstr. 9, 64287 Darmstadt, Germany \\ ${ }^{4}$ Leibniz Institute for Tropospheric Research, Permoserstr. 15, 04318 Leipzig, Germany
}

Correspondence to: R. Wagner (robert.wagner2@kit.edu)

Received: 26 May 2011 - Published in Atmos. Chem. Phys. Discuss.: 28 July 2011

Revised: 8 February 2012 - Accepted: 28 February 2012 - Published: 5 March 2012

\begin{abstract}
We have retrieved the wavelength-dependent imaginary parts of the complex refractive index for five different Saharan dust aerosol particles of variable mineralogical composition at wavelengths between 305 and $955 \mathrm{~nm}$. The dust particles were generated by dispersing soil samples into a laboratory aerosol chamber, typically yielding particle sizes with mean diameters ranging from 0.3 to $0.4 \mu \mathrm{m}$ and maximum diameters from 2 to $4 \mu \mathrm{m}$. The extinction and absorption coefficients as well as the number size distribution of the dust particles were simultaneously measured by various established techniques. An inversion scheme based on a spheroidal dust model was employed to deduce the refractive indices. The retrieved imaginary parts of the complex refractive index were in the range from 0.003 to 0.005 , 0.005 to 0.011 , and 0.016 to 0.050 at the wavelengths 955 , 505 , and $305 \mathrm{~nm}$. The hematite content of the dust particles was determined by electron-microscopical single particle analysis. Hematite volume fractions in the range from 1.1 to $2.7 \%$ were found for the different dusts, a range typical for atmospheric mineral dust. We have performed a sensitivity study to assess how accurately the retrieved imaginary refractive indices could be reproduced by calculations with mixing rule approximations using the experimentally determined hematite contents as input.
\end{abstract}

\section{Introduction}

This contribution builds on our previous aerosol chamber study on the optical properties and mineralogical composition of different Saharan mineral dust samples (Linke et al.,
2006). In the recent work, we have determined wavelengthdependent mass specific extinction, scattering, and absorption cross sections in the UV/VIS spectral region for airborne Saharan dust samples from different geographic locations and have related the deduced single scattering albedos to the iron oxide content of the samples. Such optical data are needed for a better assessment of the radiative impact of mineral dust due to the absorption and scattering of solar radiation (Sokolik and Toon, 1999). The focus on iron oxides like hematite and goethite is related to their large absorption potential at visible and near UV wavelengths (Alfaro et al., 2004; Balkanski et al., 2007; Kandler et al., 2009; Lafon et al., 2004, 2006; Sokolik and Toon, 1999).

For the analysis of our present aerosol chamber experiments on the optical properties of re-suspended mineral dust samples, we have extended our data evaluation procedure in order to deduce the complex refractive indices of the dust aerosol particles from our optical measurements. The most recent effort to derive these basic input parameters for the calculation of the single scattering properties of dust aerosols was in the context of the Saharan Mineral Dust Experiments SAMUM-1 and SAMUM-2 in Morocco and the Cape Verde Islands (Müller et al., 2010, 2011). Our studies are closely related to these experiments because some of the investigated dust samples were taken from the SAMUM-1 source region in southern Morocco and similar experimental and theoretical approaches were applied to derive the complex refractive indices. We therefore briefly review the data analysis procedure of the SAMUM field measurements. 
For a particular measurement day of SAMUM-1, Müller et al. (2010) have compared different techniques to derive the complex refractive indices of the observed dust plume, including:

- Application of a spheroidal dust model to deduce the complex refractive indices from Sun photometer observations with AERONET (Aerosol Robotic Network) (Dubovik et al., 2002b, 2006).

- Airborne in situ measurements of the particle size distributions and the aerosol absorption coefficients by a three-wavelength Particle Soot Absorption Photometer (PSAP) in combination with a Mie theory based data analysis scheme (Petzold et al., 2009).

- Application of another inversion scheme based on Mie scattering calculations using ground-based recordings of the particle number size distributions and the aerosol absorption coefficients by the Spectral Optical Absorption Photometer (SOAP) in the wavelength range from 300 to $800 \mathrm{~nm}$ as input data (Müller et al., 2009).

- Identification of the relative volume abundance of minerals by electron microscopic single particle analysis of 12900 particles. Transformation of the chemical composition to a five-component mineralogical model and application of a volume mixing rule using tabulated refractive indices of the model substances to calculate the aerosol complex refractive index of the particles (Kandler et al., 2009).

In Fig. 5 of Müller et al. (2010), the results for the real and imaginary part of the complex refractive index derived from the different techniques are compared. Although partly showing a reasonable agreement, as e.g. the spectra of the imaginary part derived from AERONET, PSAP, and SOAP, there still remain striking differences such as the entirely different wavelength dependence of the spectrum of the imaginary part retrieved from the single particle mineralogical analysis. Müller et al. (2010) have speculated that this might be due to the fact that the latter technique is unable to resolve potential amounts of soot and therefore only represents the pure dust contribution whereas the other measurements are sensitive to the total particle mixture. After applying a soot correction to the SOAP recordings (Müller et al., 2009), these data indeed show better agreement with the results from the mineralogical single particle analysis but are also associated with large uncertainty bars. Notwithstanding these recent advances from field measurements, we still consider it an urgent need to provide additional reliable data sets of complex refractive indices for dust aerosols of varying mineralogical composition, as also recently emphasised by Otto et al. (2009). Specifically addressing the absorption potential of mineral dust, we have selected for our present study dust samples with variable iron oxide content. Thereby, we want to better assess the variability of the spectrum of the imaginary part of the complex refractive index for hematite and/or goethite contents that are typical of desert dust aerosol particles. The well-characterised and controlled conditions of our laboratory experiments will help to minimise the uncertainties that are associated with the retrieved data sets.

Our findings are presented in the following manner. In Sect. 2, we describe the set-up of our aerosol chamber experiments, including generation and characterisation of the dust aerosol particles with respect to their number concentration, size, and optical properties. Details of the employed desert dust samples are summarised in Sect. 3, including their origin, elemental and mineralogical composition from bulk analyses using X-ray Fluorescence and X-ray Diffraction, as well as selected results from single particle analyses with scanning and transmission electron microscopy. In Sect. 4, we address the concept of the inversion scheme to retrieve the complex refractive indices from the optical measurements. The retrieved data sets for the five investigated probes are then presented and discussed in Sect. 5, including a comparison with available literature data, an interpretation of the results with respect to the iron oxide content of the dust samples, and a comparison of the deduced data sets with those calculated from mixing rule approaches. Section 6 finally summarises our results.

\section{Experimental}

\subsection{General procedure}

Our approach to deduce the complex refractive indices of the Saharan mineral dust particles consists of the following three steps:

- Dispersion of the dust samples into a laboratory aerosol chamber.

- Simultaneous measurements of the wavelengthresolved aerosol extinction and absorption coefficients of the dust particles as well as their number size distributions.

- Application of an inversion scheme based on a spheroidal dust model to retrieve the complex refractive indices from the optical measurements with the simultaneously recorded aerosol number size distributions as the required input data.

The set-up of the aerosol chamber experiments, as schematically shown in Fig. 1, is only slightly modified compared to our preceding work (Linke et al., 2006). The experiments were conducted in the $3.7 \mathrm{~m}^{3}$ sized NAUA chamber, a stainless steel aerosol vessel that is part of the AIDA (Aerosol Interactions and Dynamics in the Atmosphere) facility of the Karlsruhe Institute of Technology. In the preparation of each experiment, the chamber was evacuated with a vacuum pump 


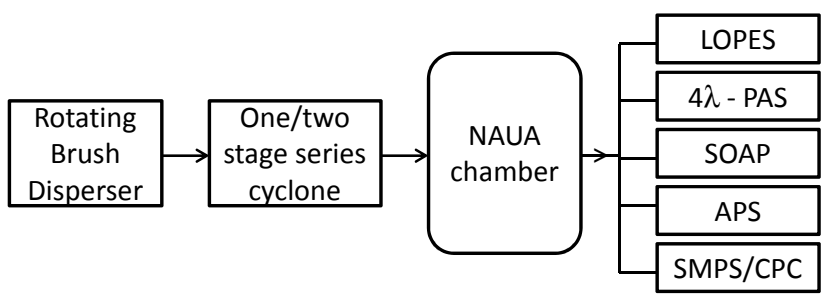

Fig. 1. Schematic set-up of the NAUA chamber experiments with dispersed Saharan soil samples, including aerosol generation and characterisation by LOPES (Long-path Extinction Spectrome-

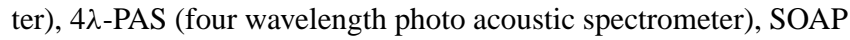
(Spectral Optical Absorption Photometer), APS (Aerodynamic Particle Sizer), and SMPS/CPC (Scanning Mobility Particle Sizer, Condensation Particle Counter).

to a final pressure of about $0.5 \mathrm{hPa}$, followed by a series of flushing cycles with particle-free synthetic air to reduce the background level of aerosol particles. The background particle number concentration was usually less than $2 \mathrm{~cm}^{-3}$. All experiments took place at ambient temperature (typically 296 K) and pressure. Since the employed aerosol and optical instruments sampled ex situ from the chamber volume, a constant flow of particle-free synthetic air of about $2 \mathrm{~m}^{3} \mathrm{~h}^{-1}$ was added to the vessel to balance for the sampling flows and to maintain ambient pressure conditions, thereby ensuring a well-defined dilution rate of the aerosol during an experiment. A mixing fan was continuously operating throughout the experiments for achieving homogeneous conditions in terms of temperature and aerosol particle number concentration inside the aerosol vessel.

After aerosol injection, the NAUA chamber acted as a reservoir for the sampling instruments. During each experiment with a given dust sample, three to four synchronised measurements of the number size distribution as well as the extinction and absorption spectrum were conducted at a time interval of about $20 \mathrm{~min}$ in order to be able to average the results for the retrieved refractive indices from multiple measurements. No significant and systematic change in the optical properties of the dust particles could be detected on the time scale of the experiments (Linke et al., 2006). Details of the aerosol generation and characterisation as well as the optical measurements are given in the following chapters.

\subsection{Aerosol generation}

The employed Saharan soil samples (see Sect. 3.1) were sieved to grain size fractions of less than $20 \mu \mathrm{m}, 20$ to $75 \mu \mathrm{m}$, and greater than $75 \mu \mathrm{m}$. For our experiments, we have used the $20-75 \mu \mathrm{m}$ size fraction and have disregarded the other fractions. Mineral dust aerosol particles were then generated and added to the NAUA chamber by dispersing the 20-75 $\mu \mathrm{m}$ sieved fraction of the dry dust samples in a rotating brush disperser (Palas, RGB 1000), de-agglomerating the finest particles in an aerosol dispersion nozzle, and removing larger par-
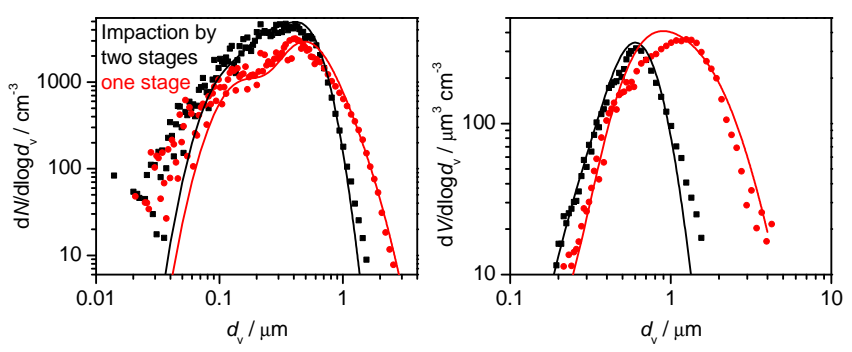

Fig. 2. Number (left panel) and volume (right panel) size distribution of dispersed SAMUM B3 dust particles. The black squares and red dots denote the combined SMPS/APS measurements for experiments with two stages (Exp. 8, Table 1) and one stage (Exp. 9) of the cyclone impaction system, respectively. The solid lines are the optimised size distributions obtained by best fitting the simultaneously recorded extinction spectra of the dust particles as described in Sect. 4.3.

ticles by one or two stages of a five-stage series cyclone system developed at Southern Research Institute (Birmingham, Alabama). Both the rotating brush disperser and the dispersion nozzle were operated with dry and particle-free synthetic air. The dispersion pressure of the nozzle was 1.5 bar. The initial particle number concentrations, as measured with a condensation particle counter (CPC3022A, TSI), were in the range from 860 to $6500 \mathrm{~cm}^{-3}$.

For all dust samples, experiments with two impaction stages of the cyclone system were conducted, yielding a cutoff $d_{(50)}$ of $1.2 \mu \mathrm{m}$ (aerodynamic diameter). This was done to minimise particle losses by sedimentation in the horizontal sampling lines. The systematic error in the deduced extinction coefficients was estimated to be less than 5\% (Linke et al., 2006). For two dust probes (Burkina Faso and SAMUM B3, see Sect. 3.1), additional experiments with only one impaction stage of the cyclone system were performed, yielding $d_{(50)}$ of $1.5-1.7 \mu \mathrm{m}$. Thereby, a significant volume fraction of the dust loading was in a size range above the threshold that contributed to extinction and absorption in the two-stage impaction experiments. Figure 2 exemplarily shows the measured number and volume size distribution of the dispersed SAMUM B3 dust sample for experiments with one and two impaction stages to underline the different cut-off $d_{(50)}$ diameters between both procedures. When using two stages of the impaction system, particles with $d_{\mathrm{v}}<1 \mu \mathrm{m}$ contribute to $91 \%$ of the total dust volume concentration whereas with one impaction stage, this fraction is only $47 \%$. Accepting a higher uncertainty due to potential sedimentation losses, these experiments might therefore shed some light on the size dependence of the deduced complex refractive indices.

\subsection{Size distribution measurements}

The number size distribution of the dust particles was measured with a Scanning Mobility Particle Sizer (SMPS, TSI, 
Table 1. Compilation of the initial dust particle number concentrations, $N_{\text {ini }}$, arithmetic averages of the number size distributions, $d_{\mathrm{v}, \text { mean }}$ (mean particle diameter), and effective diameters (Hansen and Travis, 1974), $d_{\mathrm{eff}}$, of the aerosol size distributions for all experiments with the dispersed Saharan soil samples.

\begin{tabular}{llcrcc}
\hline $\begin{array}{l}\text { Exp. } \\
\text { number }\end{array}$ & sample & $\begin{array}{c}\text { Number of } \\
\text { impaction } \\
\text { stages }\end{array}$ & $\begin{array}{r}N_{\text {ini }} / \\
\mathrm{cm}^{-3}\end{array}$ & $\begin{array}{c}d_{\mathrm{v}, \text { mean }} / \\
\mu \mathrm{m}\end{array}$ & $\begin{array}{c}d_{\mathrm{eff}} / \\
\mu \mathrm{m}\end{array}$ \\
\hline 1 & Burkina Faso & 2 & 3400 & 0.31 & 0.47 \\
2 & Burkina Faso & 1 & 860 & 0.43 & 0.97 \\
3 & Cairo 2 & 2 & 6200 & 0.35 & 0.54 \\
4 & Cairo 2 & 2 & 6500 & 0.27 & 0.44 \\
5 & SAMUM B1 & 2 & 4000 & 0.34 & 0.61 \\
6 & SAMUM B2 & 2 & 4700 & 0.35 & 0.49 \\
7 & SAMUM B2 & 2 & 4500 & 0.28 & 0.44 \\
8 & SAMUM B3 & 2 & 3100 & 0.32 & 0.53 \\
9 & SAMUM B3 & 1 & 1800 & 0.42 & 0.88 \\
\hline
\end{tabular}

mobility diameter range from 0.014 to $0.82 \mu \mathrm{m}$ ) and an Aerodynamic Particle Sizer (APS, TSI, aerodynamic diameter range from 0.523 to $19.81 \mu \mathrm{m})$. The mobility equivalent diameter $d_{\mathrm{m}}$ from the SMPS measurement is related to the volume equivalent sphere diameter $d_{\mathrm{v}}$ of the non-spherical dust particles by $d_{\mathrm{v}}=d_{\mathrm{m}} / \chi$, with $\chi$ denoting the dynamic shape factor (Hinds, 1999). From the aerodynamic diameter $d_{\mathrm{ae}}$ measured by the APS instrument, $d_{\mathrm{v}}$ is calculated using $\chi$ and the particle density $\rho_{\mathrm{P}}$ according to:

$d_{\mathrm{v}}=\sqrt{\frac{\chi}{\rho_{\mathrm{P}}}} d_{\mathrm{ae}}$.

The APS instrument detects the decreasing tail of the number size distribution towards large particle diameters which significantly contributes to the total volume concentration of the dust loading and thus to its absorption spectrum. In contrast, the mean diameter (arithmetic average) of the number size distribution of the various dust particles falls into the size regime of the SMPS measurement and is between 0.27 and $0.43 \mu \mathrm{m}$ (Table 1). To combine the SMPS and APS measurements, the particle density $\rho_{\mathrm{P}}$ was set to $2.6 \mathrm{~g} \mathrm{~cm}^{-3}$, as estimated from the mineralogical composition of the dust samples (Sect. 3) using tabulated densities for the pure minerals (Kandler et al., 2009). $\chi$ was individually adjusted for each dust type to match the SMPS and APS recordings in their overlapping size regime, yielding values between 1.17 and 1.35. Similar results for $\chi$ were recently obtained by Schladitz et al. (2009).

In addition to the SAMUM B3 example shown in Fig. 2, further number size distributions for all dust types are shown in Sect. 4.3. Table 1 summarises the initial number concentrations as well as mean and effective diameters (Hansen and Travis, 1974) for all experiments with the different dust types. Note that two identical experiment series (i.e. employing the same number of impaction stages) were conducted with the Cairo 2 and SAMUM B2 soil samples.

\subsection{Optical instrumentation}

UV-VIS extinction coefficients of the dust particles were measured with a flow tube extinction spectrometer (LOPES, Long-Path Extinction Spectrometer) (Linke et al., 2006; Schnaiter et al., 2005; Wagner et al., 2009). The stainless steel flow tube of $3 \mathrm{~m}$ length is equipped with a retro reflector for optical path folding to obtain an overall optical path length of $6 \mathrm{~m}$. The extinction spectra were recorded from 230 to $1000 \mathrm{~nm}$ with a spectral resolution of $2.5 \mathrm{~nm}$. The light is coupled in and out of the flow tubes by specially designed two-fibre optical systems in combination with a $90^{\circ}$ off-axis parabola mirror (Schnaiter et al., 2005). The transmitted light is analysed by a 2-channel UV-VIS diode array spectrometer (tec5, MCS UV-NIR) with 15 bit resolution. Taking all systematic errors into account, the measurement yields the accuracy in terms of the extinction coefficients of $40 \mathrm{Mm}^{-1}$ (Schnaiter et al., 2005; Wagner et al., 2009).

The absorption coefficients, $\sigma_{\mathrm{abs}}$, of the dust particles were deduced from measurements with the Spectral Optical Absorption Spectrometer SOAP that has already successfully been applied during the SAMUM-1 and SAMUM-2 field experiments (Müller et al., 2009, 2011). A description of the SOAP and a characterisation with the focus on absorption by mineral dust can be found in Müller et al. (2011). A few main features of the SOAP are given in the following. The dust particles are deposited onto a fibre filter (Pallflex E70/2075W) and a sample spot is illuminated by light of a deuterium/halogen lamp combination (Avantes, model AvaLight-DHS-DUV). The transmitted and reflected light is detected with two optical spectrometers (Control Development Inc., CDI2DMPP-UV-VIS) at wavelengths between 200 to $960 \mathrm{~nm}$ with an optical resolution of $25 \mathrm{~nm}$. The pixel resolution of the spectrometers is $1.5 \mathrm{~nm} / \mathrm{pixel}$ and raw data are smoothed to yield a resolution of $10 \mathrm{~nm}$. Signals at wavelengths smaller $300 \mathrm{~nm}$ are too noisy and were not used. Data are given between 305 and $955 \mathrm{~nm}$ in steps of $10 \mathrm{~nm}$. With an inversion scheme based on radiative transfer calculations of particle laden filters, particle absorption coefficients are calculated. A well known issue of filter based absorption measurements is the cross sensitivity to particle scattering. The effect of particle scattering is compensated for by measuring both the transmitted and reflected intensities. The uncertainties of SOAP are given by $\Delta \sigma_{\mathrm{abs}}= \pm\left(0.15 \sigma_{\mathrm{abs}}+\right.$ $0.02 \sigma_{\text {sca }}$ ) (Müller et al., 2011). This implies that the uncertainty is a function of the single scattering albedo.

The absorption coefficients measured by SOAP were primarily used in our inversion scheme to deduce the imaginary parts of the complex refractive index because they are continuously available over the entire wavelength range from 305 to $955 \mathrm{~nm}$. The onset of dust absorption below about $600 \mathrm{~nm}$ due to potential contributions of iron oxides can thus be accurately localised. In the spectral regime above $600 \mathrm{~nm}$ where the absorption by dust is generally low, the cross sensitivity to particle scattering of the filter-based 
absorption measurement, even if being small, provokes that the SOAP data are affected by a large uncertainty of up to $100 \%$. We therefore compare the SOAP results with additional absorption measurements using a novel four wave-

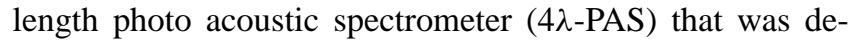
veloped at the University of Szeged, Hungary (Ajtai et al., 2010). Photo acoustic signals are obtained at the fundamental $(\lambda=1064 \mathrm{~nm})$, the doubled $(\lambda=532 \mathrm{~nm})$, the tripled $(\lambda=355 \mathrm{~nm})$, and the quadrupled $(\lambda=266 \mathrm{~nm})$ emission of a Nd:YAG laser. The $4 \lambda$-PAS instrument has been employed for the first time to measure dust absorption and its estimated uncertainty levels at the different wavelengths have previously only been derived from inter-comparison measurements with the so-called difference method for strongly absorbing soot aerosols (Ajtai et al., 2010). The presented inter-comparison of the two techniques for measuring particle absorption will therefore help to better constrain their respective measurement uncertainties.

\section{Desert dust samples}

\subsection{Origin of the employed Saharan soil samples}

Amongst the five dust samples listed in Table 1, the Cairo 2 sample has already been investigated in our previous study (Linke et al., 2006). This soil sample was collected from the Northern Sahara about $70 \mathrm{~km}$ northeast of Cairo city from a depth of $0.5 \mathrm{~m}$ and its colour is light yellow to light brown. Three further yellow brown coloured soil samples were collected during the SAMUM-1 field campaign in Morocco. The SAMUM B1 sample was collected in the Drâa valley $3 \mathrm{~km}$ west of $\mathrm{M}^{\prime}$ Hamid $\left(29^{\circ} 50.264^{\prime} \mathrm{N} 5^{\circ} 45.686^{\prime} \mathrm{W}\right)$, the SAMUM B2 sample from a Hamada close to the Oued el Atach $\left(29^{\circ} 50.974^{\prime} \mathrm{N} 6^{\circ} 0.905^{\prime} \mathrm{W}\right)$, and the SAMUM B3 sample in a dry river bed close to the border of the dry salt/silt plain of Lac Iriqui and to the sand dune fields $\left(29^{\circ} 51.721^{\prime} \mathrm{N} 6^{\circ} 9.406^{\prime} \mathrm{W}\right)$. In contrast to these comparatively light-coloured soil samples, the fifth sample, Burkina Faso, has a much darker appearance and is coloured reddish brown. The Burkina Faso soil sample consists of wind-blown material and was collected in West Africa during the AMMA (African Monsoon Multidisciplinary Analysis) dust experiment near Dano $\left(11^{\circ} 9.75^{\prime} \mathrm{N} 3^{\circ} 4.57^{\prime} \mathrm{W}\right)$ from the bank of an artificial lake which was bare of vegetation and not contaminated by sediments of the lake.

\subsection{Techniques for bulk and single particle analyses of chemistry and mineralogy}

The bulk elemental composition of each soil sample was determined for the $20-75 \mu \mathrm{m}$ size fraction by X-ray Fluorescence Analysis (XRF, Bruker AXS, SRS 303AS). Prior to the analysis, each soil sample was ignited at $1000^{\circ} \mathrm{C}$ for $1 \mathrm{~h}$ and its loss on ignition was determined. A sample mass of $200 \mathrm{mg}$ was used for the analysis.
The bulk mineralogy of the $20-75 \mu \mathrm{m}$ sieved fraction of the Burkina Faso, SAMUM B1, B2, and B3 soil samples was identified and quantified by X-ray Diffraction (XRD) using the method of reference intensity ratios (RIR) (Chung, 1974). The standard-less RIR method uses the intensities of the main reflections of the mineral phases to calculate the relative mineral abundances, relying on RIR values of the minerals that are provided by the ICDD database (ICDD, 2002). Note that only identified minerals are summed up to $100 \%$. Special care has to be taken to quantify clay minerals because they usually exhibit no or only weak reflections in randomly oriented powder samples due to their small particle size and their crystal structure (Moore and Reynolds, 1997). As described in Kandler et al. (2009), we have therefore additionally created textured samples to obtain a preferential horizontal orientation of the predominantly plate-like clay mineral particles. This induces an enhancement of their X-ray peak intensities, thereby facilitating mineral identification. To calculate the total weight fraction of clay minerals, we define a threshold size of $2 \mu \mathrm{m}$ and assign all particles below this size to the clay fraction. The two size fractions $<2 \mu \mathrm{m}$ and $>2 \mu \mathrm{m}$ were separated by gravimetrical methods and then independently weighed to evaluate the clay content (Kandler et al., 2009). In the final analysis step, a randomly oriented sample of the $<2 \mu \mathrm{m}$ clay fraction was prepared to quantify the clay minerals afore identified in the textured specimens.

In addition to the XRF and XRD analyses that were applied to the bulk samples, electron microscopy was performed on the suspended dust particles. For the single particle analyses, the dust aerosol particles were collected from the NAUA chamber with a miniature cascade impactor on carbon adhesive and on Nickel grids with formvar/carbon foil featuring a smooth surface (Plano, Wetzlar Germany). The samples were analysed by scanning electron microscopy (SEM) and transmission electron microscopy (TEM). Single particle analysis was performed with an FEI ESEM Quanta 200 FEG equipped with an EDAX analysing system for single particle applications and a FEI TEM CM200. Both instruments were equipped with an energy-dispersive X-ray detector to assess the elemental composition of the single particles. According to this elemental composition, particles were classified into major compositional groups following a set of criteria used successfully for mineral dust (e.g. Kandler et al., 2007, 2009). Five components (quartz, an "average" silicate, hematite, calcite, and sulphate) were assumed to be representative of the aerosol composition. The relative contribution of these compounds was determined from the quantification of the tracer elements $(\mathrm{Si}, \mathrm{Si}+\mathrm{Al}, \mathrm{Fe}, \mathrm{Ca}, \mathrm{S}$, respectively) for each single particle. For more details on the technique, refer to Kandler et al. (2009).

The size of the particles used for their classification into intervals was calculated as

$d_{\mathrm{e}}=\sqrt{\pi^{-14 B}}$ 
Table 2. X-ray Fluorescence Analysis of the elemental composition of the 20-75 $\mu$ m size fraction of the Saharan soil samples. The results are expressed as weight percentages (wt \%) of oxides. The standard deviation (sd) is also denoted.

\begin{tabular}{|c|c|c|c|c|c|c|c|c|c|c|}
\hline \multirow[t]{2}{*}{ Elements as oxides } & \multicolumn{2}{|c|}{ Burkina Faso } & \multicolumn{2}{|c|}{ Cairo 2} & \multicolumn{2}{|c|}{ SAMUM B1 } & \multicolumn{2}{|c|}{ SAMUM B2 } & \multicolumn{2}{|c|}{ SAMUM B3 } \\
\hline & wt $\%$ & $\mathrm{sd}$ & wt $\%$ & $\mathrm{sd}$ & wt $\%$ & $\mathrm{sd}$ & wt $\%$ & $\mathrm{sd}$ & wt $\%$ & sd \\
\hline $\mathrm{SiO}_{2}$ & 74.13 & 0.06 & 55.2 & 0.08 & 70.77 & 0.04 & 59.31 & 0.05 & 65.52 & 0.02 \\
\hline $\mathrm{Al}_{2} \mathrm{O}_{3}$ & 14.05 & 0.38 & 7.7 & 0.01 & 8.51 & 0.01 & 14.56 & 0.07 & 10.02 & 0.01 \\
\hline $\mathrm{CaO}$ & 0.22 & 0.01 & 24.3 & 0.05 & 7.85 & 0.01 & 8.30 & 0.03 & 7.54 & 0.02 \\
\hline $\mathrm{MgO}$ & $<0.1$ & & 2.9 & 0.03 & 2.90 & 0.01 & 4.38 & 0.03 & 2.55 & 0.01 \\
\hline $\mathrm{Fe}_{2} \mathrm{O}_{3}$ & 8.39 & 0.02 & 4.5 & 0.02 & 4.01 & 0.01 & 6.33 & 0.10 & 5.19 & 0.04 \\
\hline $\mathrm{K}_{2} \mathrm{O}$ & 0.39 & 0.01 & 1.18 & 0.003 & 2.27 & 0.01 & 2.99 & 0.01 & 1.96 & 0.01 \\
\hline $\mathrm{Na}_{2} \mathrm{O}$ & $<0.5$ & & 1.1 & 0.18 & $<0.5$ & & $<0.5$ & & $<0.5$ & \\
\hline $\mathrm{P}_{2} \mathrm{O}_{5}$ & 0.05 & 0.01 & 0.2 & 0.01 & 0.13 & 0.01 & 0.16 & 0.01 & 0.12 & 0.01 \\
\hline $\mathrm{TiO}_{2}$ & 1.24 & 0.02 & 1.4 & 0.07 & 1.14 & 0.06 & 1.30 & 0.02 & 1.56 & 0.01 \\
\hline Loss on ignition & 8.38 & & 19.1 & & 8.64 & & 12.55 & & 8.25 & \\
\hline
\end{tabular}

with $B$ denoting the area covered by the particle. The shape of the particles was determined as the axis ratio, AR, of an equal area ellipse for each particle, calculated as

$\mathrm{AR}=\frac{\pi L^{2}}{4 B}$

with $L$ denoting the longest projection of the particle outline. This shape information is important to cover the appropriate regime of particle aspect ratios in the computation of the optical cross sections whose methodology is described in the Sect. 4.

\subsection{Results and discussion of the dust sample analyses}

\subsubsection{Bulk analyses}

The results from the XRF measurements are shown in Table 2, summarising the weight percentages of oxides that were calculated from the measured elements. The total iron content (expressed by the method as $\mathrm{Fe}_{2} \mathrm{O}_{3}$ ) varies between 4.0 and 8.4 weight percent (wt \%) and, as expected, is highest for the reddish brown coloured Burkina Faso soil sample. For assessing the absorption potential of the soil samples, however, the total iron content must be divided into two classes. Structural iron is incorporated into the crystal structure of silicates and alumino-silicates and does not considerably influence the optical properties at visible wavelengths (Karickhoff and Bailey, 1973; Lafon et al., 2004). Only Fe(III) in the form of oxides and hydroxides $\left(\mathrm{Fe}_{2} \mathrm{O}_{3}\right.$, hematite; $\mathrm{FeOOH}$, goethite), i.e. the so-called free iron, controls absorption of light in soil samples (Lafon et al., 2004). The free-to-total iron ratio in natural soil samples can be highly variable. Lafon et al. (2006), for example, have measured percentages of free-to-total iron from $43-75 \%$ for various dust samples. Based on an average compiled from the literature, Kandler et al. (2009) have assumed that only $20 \%$ of the total iron content is hematite.
Table 3. X-ray Diffraction Analysis of the mineralogical composition of the $20-75 \mu \mathrm{m}$ size fraction of the Saharan soil samples. The results are expressed as weight percentages (wt \%) of identified minerals. Note that the Cairo 2 soil sample has not been analysed. The uncertainties are $20 \%$ for the clay minerals chlorite, kaolinite, illite, and pyrophylite, as well as $10 \%$ for all other minerals.

\begin{tabular}{lcccc}
\hline $\begin{array}{l}\text { Mineral } \\
\text { phases }\end{array}$ & $\begin{array}{c}\text { Burkina } \\
\text { Faso }\end{array}$ & $\begin{array}{c}\text { SAMUM } \\
\text { B1 }\end{array}$ & $\begin{array}{c}\text { SAMUM } \\
\text { B2 }\end{array}$ & $\begin{array}{c}\text { SAMUM } \\
\text { B3 }\end{array}$ \\
\hline Quartz & 52 & 49 & 31 & 43 \\
Hematite & 12 & 1 & 1 & - \\
Goethite & 3 & - & - & - \\
Microcline & - & 31 & 24 & 23 \\
Albite & - & 6 & 5 & 8 \\
Calcite & - & 6 & 7 & 4 \\
Dolomite & - & 4 & - & - \\
Gypsum & - & - & - & 8 \\
Muscovite & 8 & - & - & 8 \\
Chlorite & - & 1 & 21 & 4 \\
Kaolinite & 19 & 1 & 11 & - \\
Illite & 6 & 1 & - & - \\
Pyrophylite & - & - & - & 2 \\
\hline
\end{tabular}

Table 3 summarises the results from the XRD bulk analyses of the four investigated soil samples. The three SAMUM soil samples have a similar composition, with a quartz content of 31-49 wt \% and 29-37 wt \% of the feldspars albite and microcline. The lower quartz content of the SAMUM B2 sample is compensated by a higher amount of the clay minerals chlorite and kaolinite. In each sample, the iron oxide content (hematite and/or goethite) does not exceed $1 \mathrm{wt} \%$. In contrast, the Burkina Faso sample shows a very high content of iron oxides ( $15 \mathrm{wt} \%)$ with a hematite to goethite ratio of 4:1. The other dominant mineral phases are quartz ( $52 \mathrm{wt} \%)$, muscovite ( $8 \mathrm{wt} \%)$, as well as the clay minerals kaolinite and illite (19 and $6 \mathrm{wt} \%$, respectively). Compared to the total 


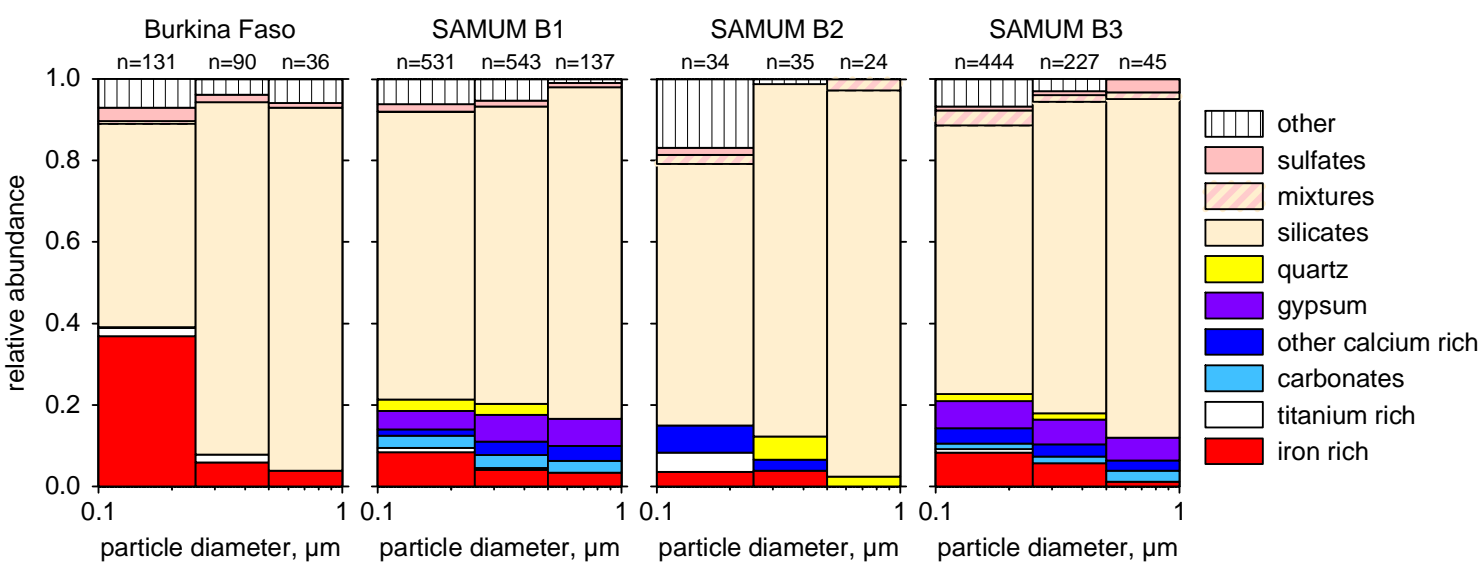

Fig. 3. Size-resolved composition of the dispersed soil samples. The numbers above the single bars show the number of analysed single particles in this size interval. Particles are weighted according to their volume inside the single size intervals.

Table 4. Relative volume abundance of model substances derived from single particle analysis. The particle number of SAMUM B2 was not sufficient for such an analysis.

\begin{tabular}{lccc}
\hline Component & $\begin{array}{c}\text { Burkina } \\
\text { Faso }\end{array}$ & $\begin{array}{c}\text { SAMUM } \\
\text { B1 }\end{array}$ & $\begin{array}{c}\text { SAMUM } \\
\text { B3 }\end{array}$ \\
\hline "Quartz" & 0.004 & 0.012 & 0.006 \\
"Hematite" & 0.027 & 0.016 & 0.011 \\
"Calcite" & 0.001 & 0.092 & 0.055 \\
"Average Silicate" & 0.949 & 0.842 & 0.867 \\
"Sulphate" & 0.019 & 0.037 & 0.061 \\
\hline
\end{tabular}

iron contents determined by the XRF analyses which only vary by a factor of about two between the Burkina Faso and the three SAMUM soil samples, the XRD bulk analyses suggest that the absorption potential of the dispersed Burkina Faso soil sample should be at least one order of magnitude larger than that of the other soil probes. In the next section, we will investigate whether this large variation in the iron oxide content of the bulk soil samples is also evident in the actual aerosol composition of the dispersed dust particles, as inferred from electron-microscopic single particle analysis.

\subsubsection{Single-particle analyses}

Figure 3 shows the size-resolved composition of the Burkina Faso and the SAMUM B1, B2, and B3 samples from the SEM analyses. In contrast to the bulk samples that were dominated by quartz (silicon dioxide), all aerosol samples are dominated by the silicate particle group (clay minerals and/or feldspars, indicated by the elements $\mathrm{Si}$ and $\mathrm{Al}$, with minor contents of $\mathrm{Na}, \mathrm{Ca}, \mathrm{K}$, and/or $\mathrm{Fe}$, excluding quartz). As expected from other investigations (e.g. Kandler et al., 2009), the obviously larger quartz particles from the parent soils were not present any more in the dispersed aerosol. A common feature for all samples is the increase in the abundance of iron-rich particles with decreasing particle size. In the Burkina Faso sample, this abundance of iron-rich particles is significantly higher than in the SAMUM samples, but the difference is much lower than the difference between the parent soil samples (Table 3). It can be concluded that though iron seems to be associated rather with small particles in the aerosol - the largest amount of hematite and goethite was present in large grains removed by the dispersion of the soil samples. The total hematite volume contribution to the aerosol, as calculated by the five component mixing model, is 2.7 vol \% for the Burkina Faso sample and only 1.1 to 1.6 vol \% for the SAMUM samples (Table 4). As in Kandler et al. (2009), $20 \%$ of the total iron content were attributed to hematite. Another visible difference between the Burkina Faso sample and the SAMUM samples lies in the presence of calcium-rich particles, which are absent in the Burkina Faso sample, but contribute with up to 9.2 vol $\%$ to the SAMUM samples. This difference is in accordance with the parent topsoil composition of the source regions (Claquin et al., 1999). In Sect. 5.2, we employ the deduced aerosol composition from Table 4 as input to compute the imaginary parts of the complex refractive index of the dust particles with various mixing rule approaches.

The particles were classified into compositional groups to enable the calculation of volume contributions; however, even though this complexity cannot currently be regarded by our model, it should not be concealed that each single particle can possess a unique composition and structure. Figure 4 shows a scatter plot of iron index versus silicon index. The element index is defined as the atomic ratio of the concentration of the element considered and the sum of the concentrations of the elements $\mathrm{Na}, \mathrm{Mg}, \mathrm{Al}, \mathrm{Si}, \mathrm{P}, \mathrm{S}, \mathrm{Cl}, \mathrm{K}, \mathrm{Ca}, \mathrm{Ti}, \mathrm{Cr}$, $\mathrm{Mn}$, and $\mathrm{Fe}$. It becomes instantaneously visible that (a) the average iron index of the silicate particles is larger in Burkina Faso (cluster around silicon index 0.45), and that (b) there exists a group of small particles rich in iron (cluster at silicon 


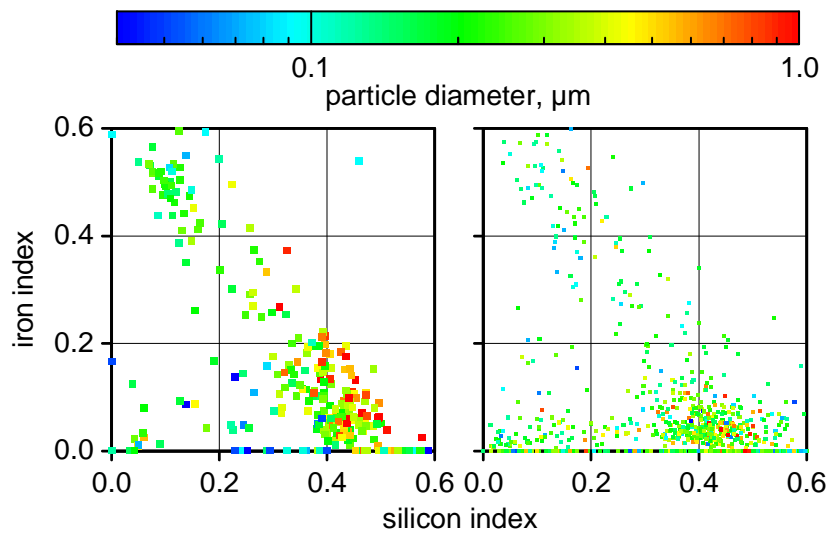

Fig. 4. Iron index versus silicon index for the Burkina Faso (left) and SAMUM B3 (right) samples. Particle diameter is coded as symbol colour. Element indices are defined as atomic ratio of the element to the sum of $\mathrm{Na}, \mathrm{Mg}, \mathrm{Al}, \mathrm{Si}, \mathrm{P}, \mathrm{S}, \mathrm{Cl}, \mathrm{K}, \mathrm{Ca}, \mathrm{Ti}$, and $\mathrm{Fe}$.

index 0.1 and iron index 0.5 ), which is more abundant in the Burkina Faso than in the SAMUM B3 sample. Apart from these clusters, particles with variable compositions exist. For this reason, the five component mixing model described above was calculated on a single particle basis rather than based on the identified particle groups.

To illustrate the complex structure of even single particles, Fig. 5 shows an example from the Burkina Faso dust sample. The particle is composed of silicate $(\mathrm{Si}+\mathrm{Al})$ particles with small grains of nanometre-sized crystallites of iron oxides, either as inclusions or on the surface, which have also been described for atmospheric aerosol (Lieke et al., 2011). These iron oxide nanocrystallites were determined to consist of hematite by selected area diffraction (SAED) in the TEM. Lattice spacings measured in the SAED patterns did match with hematite, but neither with magnetite nor goethite. High resolution TEM images of those iron enriched locations on the particles revealed primary crystallite grains of five to some tens of nanometres size. Additional elemental mappings (not shown) revealed that iron-rich and also titaniumrich crystallites on and attached to particles are a common feature of the investigated dust, which was also reported for atmospheric desert aerosol (e.g. Scheuvens et al., 2011). The complexity of the internal particle structure must be kept in mind when comparatively simple mixing rule approaches are applied to compute the complex refractive index of the dust particles (Sect. 5.2).

Addressing the shape of the dust particles, Fig. 6 shows the density distribution of the axis ratios (AR) as normalised values per size interval as well as a parameterised curve (for parameterisation refer to Kandler et al., 2007). While there is no considerable difference between the SAMUM B1 and B3 samples (median AR for B1/B2/B3: 1.85/1.93/1.78; particle number of B2 was not sufficient for parameterisation), the Burkina Faso sample shows slightly lower axis ratio val-

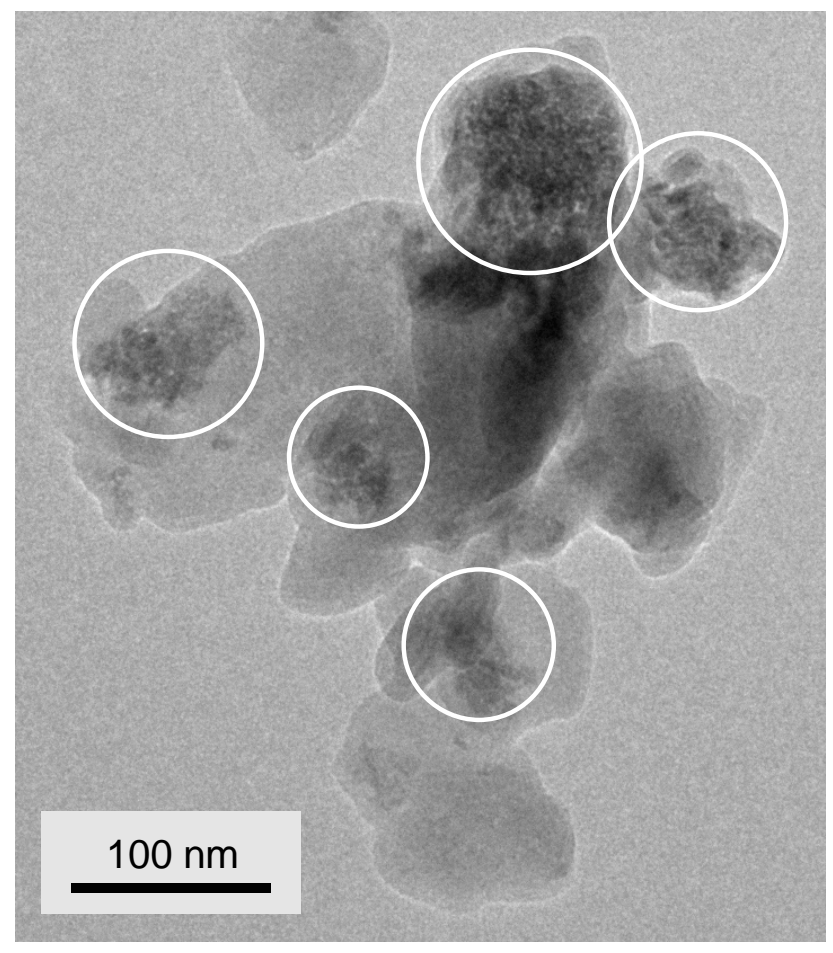

Fig. 5. Transmission electron microscopy bright-field image of a silicate particle with grains of nanometre-sized crystallites of iron oxides (marked by white circles).

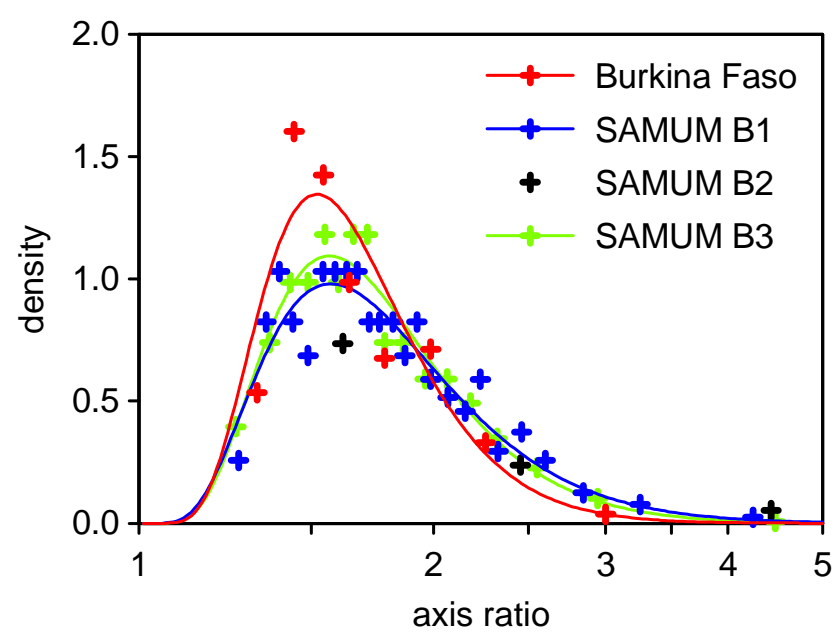

Fig. 6. Ellipse axis ratio density distributions for the soil-generated aerosol samples. The solid lines are modified log-normal functions fitted to the data. For the function description refer to Kandler et al. (2007). SAMUM B2 did not yield enough particle counts for a parameterisation.

ues (median 1.69), i.e. less elongated particles. Overall, the $\mathrm{AR}$ values found in this laboratory experiment are slightly higher than those encountered in ambient dust aerosol, featuring median values of 1.6 to 1.7 west of Africa with similar 
parent soils (Kandler et al., 2007, 2009, 2011). This might be related to the aerosol generation mechanism because the dispersion of the soil samples including one or two impaction stages is, of course, just a surrogate for the natural particle production.

\section{Inversion scheme}

In this chapter, we explain the details of our inversion scheme to deduce the wavelength dependent imaginary part of the complex refractive index of the airborne dust particles from their optical spectra and their simultaneously recorded number size distributions. In Sect. 4.1, we describe the computation of a scattering database on a four-dimensional parameter space which serves as a look-up table in the retrieval procedure and thus limits the computational burden of our analysis. The database contains the extinction and absorption cross sections of randomly-oriented spheroidal particles as a function of their size parameter, aspect ratio, and the real and imaginary parts of the complex refractive index. In Sect. 4.2, we present basic considerations on the appropriate inversion method for our retrieval problem. Our actual inversion scheme that was developed from these initial considerations is then thoroughly described in Sect. 4.3.

\subsection{Computational methods: a database of optical cross sections for randomly oriented spheroidal particles}

As in similar computational studies on the optical properties of mineral dust, we have employed a spheroidal model to compute the shape dependent extinction and absorption cross sections of the irregularly shaped dust particles (Dubovik et al., 2006; Meng et al., 2010; Merikallio et al., 2011; Mishchenko et al., 1997; Otto et al., 2009; Wiegner et al., 2009; Yang et al., 2007). A random orientation of the particles was assumed. The aspect ratio $\varepsilon$ of a spheroid was defined as the ratio of its horizontal to rotational axis (Mishchenko and Travis, 1998). Both oblate $(\varepsilon>1)$ and prolate $(\varepsilon<1)$ particle shapes were considered in the calculations. Given the aspect ratio density distribution obtained from the SEM single particle analyses (Fig. 6), a maximum asphericity of $\varepsilon=4$ and $\varepsilon=0.25$ was assumed for oblate and prolate particle shapes, respectively. Altogether, 29 logarithmically equidistant aspect ratios between 0.25 and 4 were considered. For each aspect ratio, the optical cross sections were computed for 88 logarithmically spaced equal-volume sphere size parameters $x_{\mathrm{v}}\left(x=\pi d_{\mathrm{v}} / \lambda\right)$ between 0.02 and 50, 11 equidistantly spaced real parts of the complex refractive index between 1.3 and 1.7 , and 15 logarithmically spaced values between 0.0001 and 0.1 for the imaginary part of the complex refractive index, summing up to 14520 individual calculations. The optical cross sections for intermediate values of $x_{\mathrm{v}}$ and the complex refractive index are obtained by spline interpolation from the pre-computed data.
Details of the applied computational methods are summarised in Appendix A1. In Appendix A2, selected results from the database are discussed to underline the shape dependency of the optical cross sections of the randomly oriented spheroids. This analysis contains necessary information to understand the shape dependency of the retrieval results and we will refer to these findings when discussing our inversion scheme in Sect. 4.3.

\subsection{Retrieval approach: basic considerations}

Four quantities were independently measured for each desert dust sample in our experiments: the wavelength resolved extinction and absorption coefficients, $\sigma_{\text {ext }}$ and $\sigma_{\text {abs }}$, the number size distribution, and the frequency distribution of aspect ratios. Exploiting all measurements, our initially designed inversion scheme to retrieve the wavelength dependent complex refractive index of the dust aerosols was as follows. Based on an initial guess for the real, $n_{\text {ini }}$, and imaginary part, $k_{\text {ini }}$, of the complex refractive index at a given wavelength, the size- and shape averaged extinction and absorption coefficients of the aerosol particles were calculated from the database using the measured number size distribution and frequency distribution of aspect ratios as input, yielding the quantities $\sigma_{\text {ext,calc }}\left(n_{\text {ini }}, k_{\text {ini }}\right)$ and $\sigma_{\text {abs,calc }}\left(n_{\text {ini }}, k_{\text {ini }}\right)$. Then, the combined root mean square (RMS) deviations between the measured quantities from LOPES and SOAP/4 $\lambda$-PAS, $\sigma_{\text {ext,meas }}(n, k)$ and $\sigma_{\text {abs,meas }}(n, k)$, and the calculated values were computed (Eq. 4).

$$
\begin{aligned}
& \operatorname{RMS}_{\text {abs }+ \text { ext }}(n, k)=\underbrace{\left[\frac{\sigma_{\text {abs, meas }}(n, k)-\sigma_{\text {abs,calc }}\left(n_{\text {ini }}, k_{\text {ini }}\right)}{\sigma_{\text {abs,calc }}\left(n_{\text {ini }}, k_{\text {ini }}\right)}\right]^{2}}_{\text {RMS }_{\text {abs }}} \\
& +\underbrace{\left[\frac{\sigma_{\text {ext }, \text { meas }}(n, k)-\sigma_{\text {ext }, \mathrm{calc}}\left(n_{\mathrm{ini}}, k_{\mathrm{ini}}\right)}{\sigma_{\text {ext }, \mathrm{calc}}\left(n_{\mathrm{ini}}, k_{\mathrm{ini}}\right)}\right]^{2}}_{\mathrm{RMS}_{\mathrm{ext}}}
\end{aligned}
$$

Equation (4) holds for each wavelength step of the extinction and absorption measurements. Then, the added $\mathrm{RMS}_{\mathrm{abs}+\mathrm{ext}}$ value for extinction plus absorption was minimised by optimising the initial guess values $n_{\text {ini }}$ and $k_{\text {ini }}$, yielding the true values for $n$ and $k$ at each wavelength. Because the absorption spectrum is mainly determined by the magnitude of $k$, and the extinction spectrum, for weakly absorbing particles, is mainly governed by the magnitude of $n$, the minimisation of the combined $\mathrm{RMS}_{\mathrm{abs}+\mathrm{ext}}$ value should yield a unique retrieval result for both $n$ and $k$. We have encountered, however, two severe problems when applying this inversion technique.

Firstly, as elaborated in detail in Sect. 4.3 of our previous discussion paper (Wagner et al., 2011), test calculations have revealed that unique retrieval results for both $n$ and $k$ could only be obtained at visible wavelengths but not towards the UV spectral region. Here, the value for the real part of the 
complex refractive index was not constrained by simultaneous extinction and absorption measurements for the particle size range covered in our experiments. Secondly, we have observed a significant spread in the retrieved $n$ values at visible wavelengths for the three samples SAMUM B1, B2, and B3 which have a similar mineralogical composition. The deduced $n$ values for the three samples were in the range from 1.35 to 1.65 . Since this variation is much larger than that expected from previous literature studies and the mineralogical composition as described above, we attribute it to uncertainties in the size distribution measurements, induced e.g. by inaccurate choices for $\chi$ and $\rho_{\mathrm{P}}$ from Eq. (1) to combine the SMPS and APS data. These inherent uncertainties associated with the sizing of the dust particles are well-documented in the literature (Reid et al., 2003) and directly affect the accuracy of the retrieval results for the complex refractive index. We have addressed these two problems as follows.

Firstly, we chose to prescribe the real part of the complex refractive index to a constant value for all wavelengths in the UV-VIS spectral region. This approach seems justified because the real part of the mineral dust complex refractive index, in contrast to its imaginary part, usually shows less variation with the wavelength in the considered spectral regime. Petzold et al. (2009), for example, have derived almost constant $n$ values between 1.55 and 1.56 from the analysis of the PSAP data during SAMUM-1. Kandler et al. (2009) report a slight increase of $n$ towards UV wavelengths, yielding $n=1.582$ at $350 \mathrm{~nm}$ as volume-weighted average. Based on previous data from the literature, Müller et al. (2009) have assumed the real part of the complex refractive index to be 1.53 , independent of the wavelength, in order to correct the SOAP absorption measurements for scattering. AERONET retrievals for different desert dust sites have yielded $n$ values ranging from 1.48 to 1.56 (Dubovik et al., 2002a).

After prescribing the value for the real part of the complex refractive index, the measurement of the extinction spectrum with LOPES at first became redundant in the retrieval scheme because obviously only the absorption spectrum measured with SOAP/4 $\lambda$-PAS was still needed to deduce the imaginary part of the complex refractive index. But the extinction spectrum proved to be useful for addressing the remaining retrieval problem associated with the uncertainties of the size distribution measurements. We chose to use the extinction spectrum as a reference measurement for optimising the measured number size distribution of the dust particles. This modified inversion scheme will be described in detail in the following section.

\subsection{Inversion scheme: optimising the measured number size distributions of the dust particles}

\subsubsection{General procedure}

In the initial step of our inversion scheme, each measured number size distribution was fitted by two or three log-

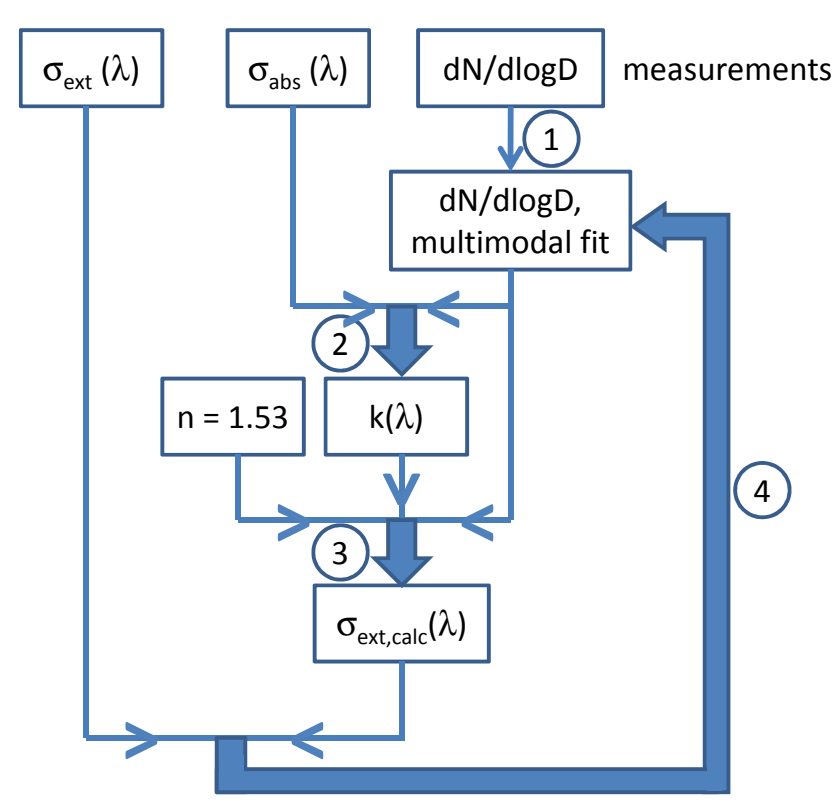

Fig. 7. Flowchart of the modified retrieval approach to deduce the wavelength dependent spectrum of the imaginary part of the complex refractive index, $k(\lambda)$, from the optical measurements. The concept involves the optimisation of the measured number size distribution of the dust particles. The individual retrieval steps 1-4 are explained in the text.

normal modes (step 1 in the retrieval flowchart shown in Fig. 7). We have then calculated the size-averaged extinction spectrum for the fitted number size distribution from the pre-computed look-up tables, using, as stated above, a constant value for $n$ and an initial guess for the wavelengthdependent $k$ spectrum (step 3). The latter was retrieved from the measured absorption spectrum using the fitted number size distribution as input, i.e. for each wavelength step of the $\mathrm{SOAP} / 4 \lambda$-PAS absorption measurement, $k$ was optimised to minimise the root-mean square deviation, $\mathrm{RMS}_{\mathrm{abs}}$, between the measured absorption coefficient and the size-averaged value computed from the look-up tables for a fixed $n$ (step 2). Afterwards, the parameters of the two or three individual log-normal modes (number concentration, mode width, and count median diameter) of the dust particle number size distribution were optimised to obtain best agreement between the measured and the computed extinction spectrum (step 4). The total number concentration, however, was prescribed to that measured with the condensation particle counter, i.e. only the distribution of the total dust particle number concentration amongst the two or three individual modes was varied. The modified number size distribution from this first iteration step was used to obtain an improved guess for the $k$ spectrum (step 2), which then was used to further optimise the number size distribution in second iteration steps 3 and 4 (Fig. 7). In all these steps, the downhill simplex method was used as the optimisation technique (Press et al., 1992). As evident 

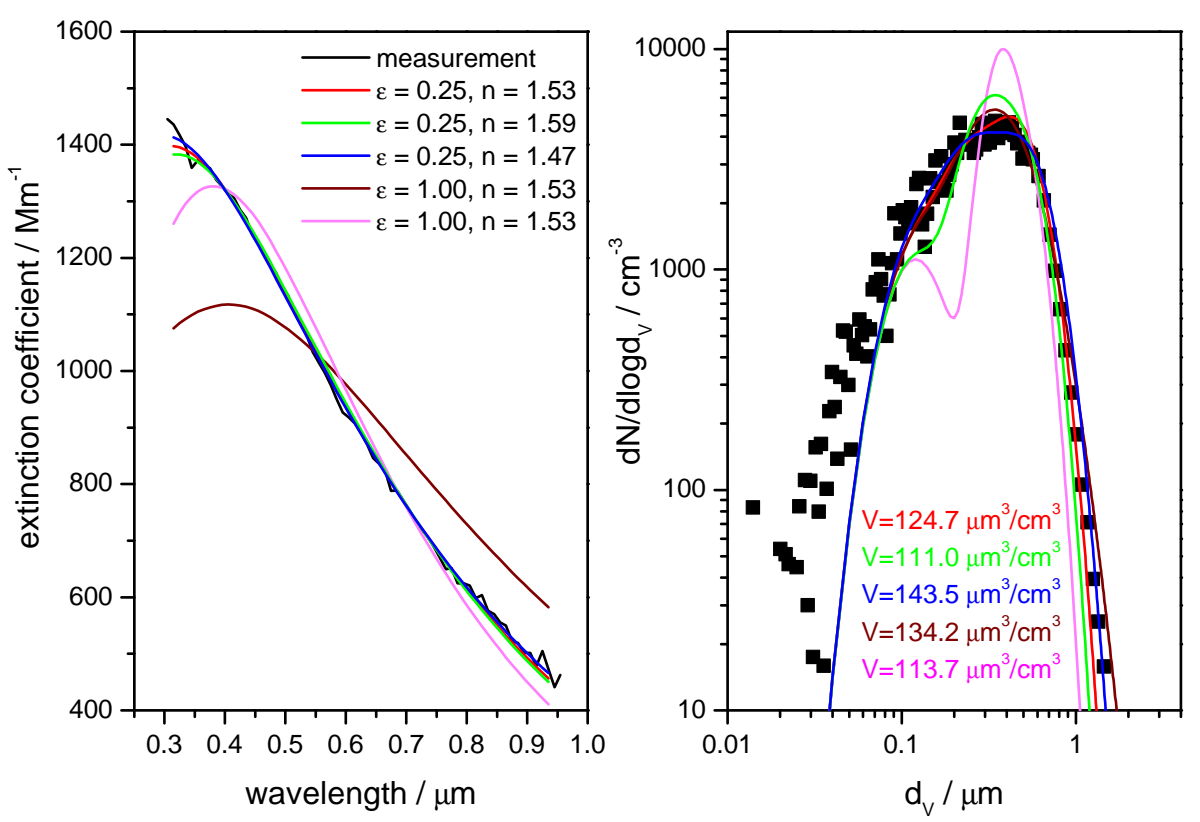

Fig. 8. Measured extinction spectrum (left panel, black line) and number size distribution (right panel, black squares) of dispersed dust particles from the SAMUM B3 soil sample (Exp. 8). The recordings are compared to best fit results for different assumptions on the particle shape and the real part of the complex refractive index (coloured lines), see text for details. The total volume concentrations, $V$, of the dust particle loading, as calculated from the various fitted number size distributions, are indicated in the right panel.

from Fig. 7, the inversion scheme directly combines the optimisation of the measured number size distribution (step 4) with the retrieval of the spectrum of the imaginary part of the complex refractive index from the absorption measurements (step 2). The retrieved $k$ data sets will be presented and discussed in Sect. 5. Before, we address two key issues associated with the inversion scheme which still have to be discussed, namely its dependency on the assumed shape of the dust particles and its uncertainty.

\subsubsection{Influence of particle shape}

Figure 8 shows exemplary results of the outlined retrieval procedure for Exp. 8 (SAMUM B3 sample, two impaction stages, see also Fig. 2). The left panel contains the measured extinction spectrum (black line) and various best fitted extinction spectra (coloured lines) for different assumptions on the value for the wavelength independent real part of the complex refractive index and for the aspect ratio of the dust particles. The right panel depicts the measured number size distribution from the combination of SMPS and APS (black squares) and the optimised number size distributions that yielded the computed extinction spectra shown in the left panel (same colour code). Also denoted in the right panel are the total dust volume concentrations, $V$, for the various fit scenarios. The red, green, and blue traces all correspond to calculations for elongated dust particles with an aspect ratio of $\varepsilon=0.25$ but choosing different values for $n$, thereby covering the variability of this quantity that has been observed in previous studies. For this particle shape, the measured number size distribution, in particular for $n=1.53$ (red line) and $n=1.47$ (blue line), only needs to be slightly modified to obtain a very good agreement between the computed and the measured extinction spectrum.

The two further coloured lines in Fig. 8 correspond to fit results for spherical particles with $\varepsilon=1$. The brown line in the left panel shows the extinction spectrum of the dust particles for the initially fitted, i.e. not yet optimised number size distribution. Apparently, a spherical particle shape greatly fails to reproduce the measured habitus of the extinction spectrum for a size distribution that is similar to the measured one. In particular, the continuous increase in the extinction coefficient towards UV wavelengths is not mimicked by the spherical particles. The computed extinction spectrum, in the direction from longer to shorter wavelengths, can be regarded as an image of the trace of the extinction efficiency with increasing size parameter (see middle panel of Fig. A2 in Appendix A). The maximum of the extinction coefficient at about $400 \mathrm{~nm}$ for the $\varepsilon=1$ computations thereby reflects the pronounced first interference maximum in the $Q_{\text {ext }}$ curve. This maximum is absent in the $\varepsilon=0.25$ computations because the interference structure is distorted so that the first maximum is shifted to larger size parameters. An elongated spheroid is obviously a much more suited shape representation than a sphere to model the extinction coefficients of dust particles with sizes that partly extend into the regime that is governed by the interference structure. As 
explained in Appendix A2, the trace for $C_{\text {ext }}$ of the $\varepsilon=0.25$ spheroid closely agrees with that of an aggregate particle (see top panel of Fig. A2) up to a diameter $d_{\mathrm{v}}$ of about $1.1 \mu \mathrm{m}$, i.e. for the complete range of particle sizes covered by the experiment (see right panel of Fig. 8). This underlines that an aggregate like shape is a good proxy for calculating the extinction cross sections of the dispersed dust particles in our experiments.

The second fit example for $\varepsilon=1$ which is shown in Fig. 8 (magenta line) represents the optimised number size distribution after two overall iteration steps. It is obvious that the measured number size distribution has to be significantly distorted in order to obtain a reasonable agreement between the measured and the computed extinction spectrum for $\varepsilon=1$. In a recent environmental aerosol chamber study on the extinction spectra of key components of mineral dust aerosol, Mogili et al. (2007) have observed an excellent agreement between measured extinction spectra in the UV-VIS spectral range and those calculated from Mie theory simulations. The retrieved log-normal number size distributions, however, were not compared to independent measurements. Thus, likewise to the optimised number size distribution for $\varepsilon=1$ in our study, the true number size distributions of the samples investigated by Mogili et al. (2007) might also have been deformed to obtain the good agreement between the measured extinction data and the Mie-based simulations.

Similar to the Mie calculations shown in Fig. 8, the measured number size distribution also had to be significantly distorted for matching the extinction spectrum when applying the shape distribution of the dust particles inferred from the two-dimensional electron microscopy images (Fig. 6) in the retrieval. This is because the axis ratio density distributions are centred at quite compact particle shapes whose extinction efficiency curves do not significantly differ from the Mie result, as evident e.g. when comparing the green $(\varepsilon=1)$ and yellow $(\varepsilon=1.64)$ computations of $Q_{\text {ext }}$ in the middle panel of Fig. A2. This might be partly related to deficiencies when using two-dimensional images to infer three-dimensional particle properties due to potential preferred particle orientation on the substrate during and after impaction. Chain-like particles, e.g. would orientate in parallel to the streamlines in an impactor, meaning that they would lie flat on the surface. It is less probable, however, that this also holds for the dust particles because they are not so extreme in shape and the orientation force should therefore be much weaker.

More likely, at least in the spectral regime governed by the interference structure, a compact spheroidal shape is simply not adequate to describe the extinction coefficients of an irregularly shaped dust grain (Fig. 5) even if the latter's ellipsoidal envelope matches the aspect ratio of the spheroid. We have therefore optimised the measured number size distributions for all experiments using prolate spheroids with $\varepsilon=0.25$ as the particle shape, i.e. have not employed the density distribution from Fig. 6 . Further comparisons between the measured and the optimised number size distribution for different experiments are compiled in Fig. 9.

The $\varepsilon=0.25$ spheroid is also an appropriate representative for the absorption properties of the dust particles because the larger surface area of these elongated spheroids better matches the actual surface area of the irregularly formed dust grains than the smaller surface area of the comparatively compact equal-volume spheroidal shapes with the aspect ratio of ellipses fitted to the projected particle areas in the electron microscopy images. As explained in Appendix A2, this aspect only addresses the two experiments with a single impaction stage (Table 1) where the absorption cross sections, $C_{\text {abs }}$, of the largest dust grains from the size distribution will start to become slightly sensitive to their surface area.

\subsubsection{Uncertainty estimation}

Notwithstanding the uncertainty with respect to the accurate shape representation of the dust grains for modelling extinction in the regime governed by the interference structure, its quantitative impact on the accuracy of the retrieved $k$ data sets (step 2 in Fig. 7) is rather low.

Although the application of a spherical shape for fitting the extinction spectrum severely distorts the measured number size distribution, the total volume concentration, $V$, of the dust aerosol inferred from the optimised number size distribution for $\varepsilon=1$ deviates by less than $10 \%$ from that calculated for the $\varepsilon=0.25$ fit. The retrieval results for $k(\lambda)$ when using either the input parameters $n=1.53 ; \varepsilon=0.25$ or $n=1.53 ; \varepsilon=1$ in our inversion scheme differ by at most $9 \%$. The similarity in the uncertainties for $V$ and $k(\lambda)$ underlines that absorption by the dust particles is still volume-dominated although the particle sizes are beyond the Rayleigh regime characterised by the proportionality between $C_{\text {abs }}$ and $V$ (Bohren and Huffman, 1983). Only when applying the two different sets of input parameters for analysing the experiments with a single impaction stage (Table 1), an additional offset of at most $5 \%$ between the $k(\lambda)$ retrievals became apparent for wavelengths below $450 \mathrm{~nm}$. This is because the size-averaged absorption cross sections become slightly dependent on the particle shape below this threshold (Appendix A2, Fig. A2).

Another uncertainty arises from the choice for the (wavelength-independent) value for the real part of the complex refractive index. Like in Müller et al. (2009), we have used $n=1.53$ for all our $k(\lambda)$ retrievals presented in the next section (WMO, 1986). As obvious from the sensitivity study shown in Fig. 8, an absolute uncertainty of 0.06 in the magnitude of the $n$ value with respect to $n=1.53$, i.e. $n=1.53 \pm 0.06$, provokes a change in $V$ of at most $15 \%$. The maximum deviation of the retrieval results for $k(\lambda)$ for the input parameter sets $n=1.59 ; \varepsilon=0.25$ or $n=1.47$; $\varepsilon=0.25$ from those for $n=1.53 ; \varepsilon=0.25$ was $13 \%$. 

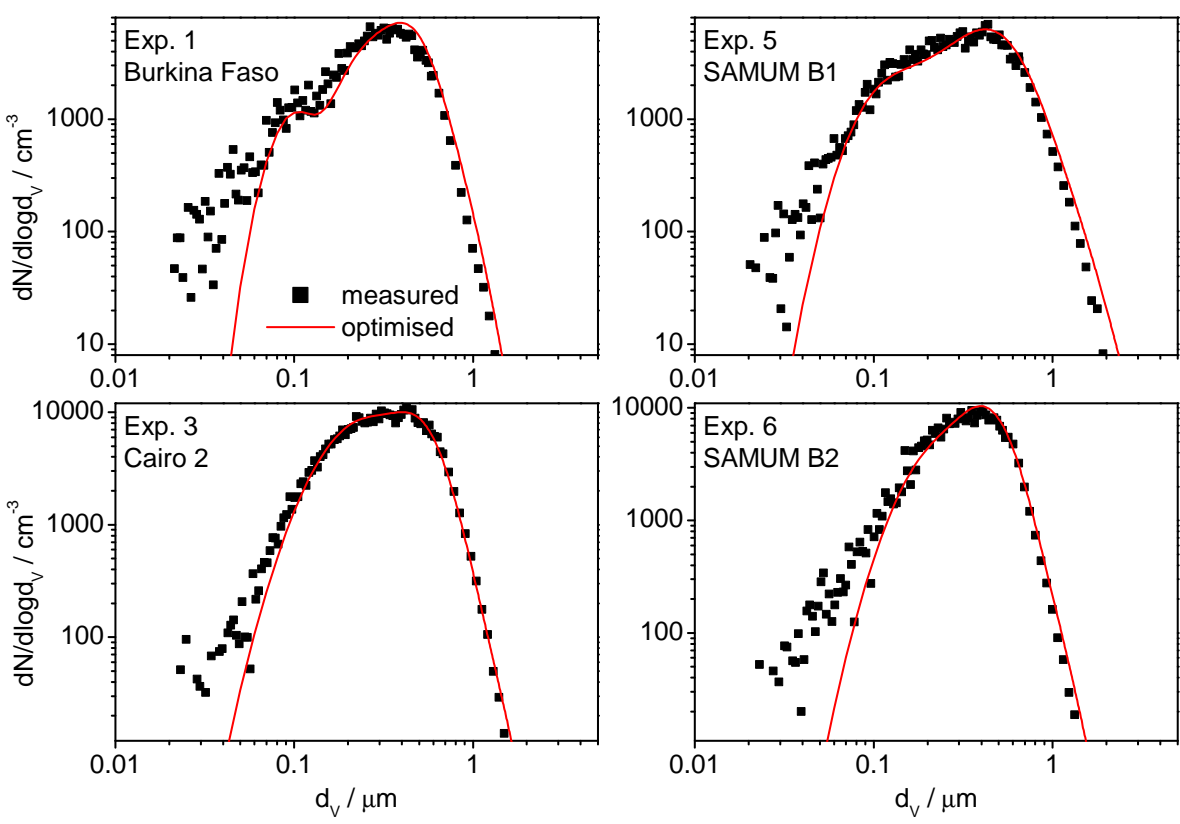

Fig. 9. Comparison between measured (black squares) and optimised (red lines) number size distributions for four further experiments with the dispersed Saharan dust samples, using $n=1.53$ and $\varepsilon=0.25$.

\section{Retrieval results and discussion}

\subsection{The retrieved spectra of the imaginary part of the complex refractive index: overview and error analysis}

Figure 10 shows a compilation of our retrieval results for the spectra of the imaginary part of the complex refractive index of the dispersed Saharan soil samples which were derived from the SOAP absorption measurements. To illustrate the degree of variation in the retrieval results, the upper two panels depict all individual $k$ spectra that were deduced from repetitive synchronised measurements of the extinction and the absorption spectrum as well as the number size distribution within experiment series conducted with the SAMUM B3 and Cairo 2 soil samples. Mean $k$ spectra and their standard error, as calculated from all individual measurements and thus representing the precision of the SOAP instrument, are shown in red. Concerning the results for the SAMUM B3 sample, no systematic deviation between the $k$ spectra from the experiment series with one and two impaction stages can be observed. The same behaviour was found for the two respective experiment series with the Burkina Faso soil sample. A potential size dependence of the refractive index for $<1 \mu \mathrm{m}$ and $>1 \mu \mathrm{m}$ sized dust grains (see Fig. 2) is therefore too small to be resolved within the accessible precision of the measurements and the accuracy of the retrieval approach.

In the bottom panel of Fig. 10, all mean $k$ spectra of the five investigated dust samples are compared. All dust aerosols feature a low, constant background absorption value for wavelengths larger than about $600 \mathrm{~nm}$. This background level is between 0.002 and 0.003 for the Burkina Faso, Cairo 2, and SAMUM B3 dust samples whereas it is clearly increased to about 0.005 for the SAMUM B1 and SAMUM B2 samples. Below $600 \mathrm{~nm}, k$ starts to increase steadily towards the UV regime for all dust probes. The $600 \mathrm{~nm}$ threshold corresponds to the onset of absorption in hematite (Sokolik and Toon, 1999). It therefore seems reasonable to relate the variations in the $k$ spectra of the different dust samples to their varying hematite content (see Sect. 3.3). The outstanding role of the reddish brown coloured Burkina Faso dust sample in comparison with the other four yellow brown coloured soil samples immediately becomes obvious. Towards UV wavelengths, the value for $k$ increases up to about 0.05 for the dispersed Burkina Faso soil sample whereas maximum values between 0.016 and 0.022 are reached for the other dust types.

The small errors bars in the mean $k$ spectra from the SOAP retrievals reflect the good precision of the instrument. This good reproducibility, however, is no criterion for the absolute accuracy of the filter-based absorption measurement which is affected by the cross sensitivity to particle scattering (Sect. 2.4). When rigorously applying the formula from Müller et al. (2011) to calculate the maximum uncertainties of the SOAP data, $\Delta \sigma_{\mathrm{abs}}= \pm\left(0.15 \sigma_{\mathrm{abs}}+0.02 \sigma_{\mathrm{sca}}\right)$, the errors in the retrieval results for $k$ in the strongly absorbing spectral regime towards UV wavelengths are still smaller than the observed variability of the $k$ data between e.g. the Burkina Faso and the three SAMUM soil samples. On the other hand, the retrieval errors would be larger than 

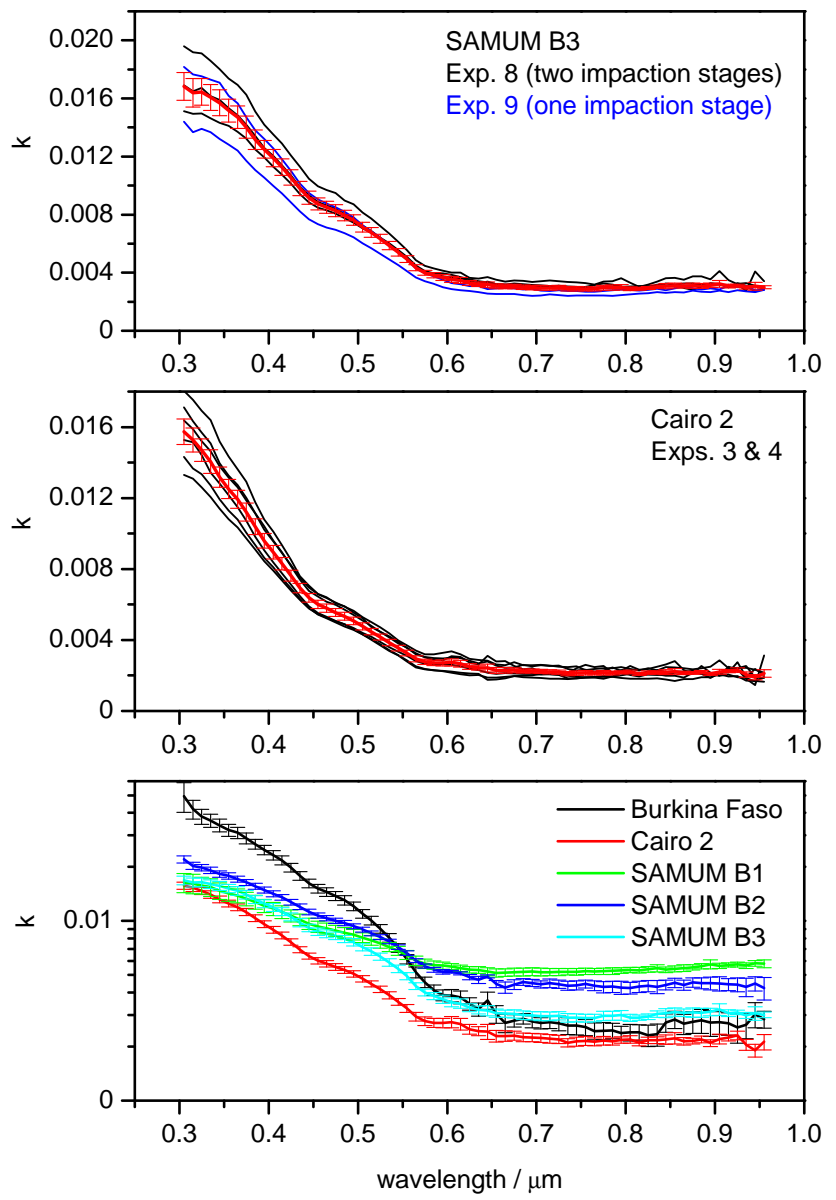

Fig. 10. Top panel: retrieved spectra of the imaginary part of the complex refractive index, $k$, for the SAMUM B3 dust sample from individual SOAP absorption measurements during Exp. 8 (black lines) and Exp. 9 (blue lines). The resulting mean $k$ spectrum and its standard error, denoting the variability between the individual measurement cycles, are shown in red. Middle panel: retrieved $k$ spectra for the Cairo 2 dust sample from six individual measurements with SOAP during Exps. 3 and 4 (black lines). As in the top panel, the mean $k$ spectrum and its standard error are shown in red. Bottom panel: Mean $k$ spectra and their standard error for all five investigated dust samples on a logarithmic $k$ scale (SOAP retrievals).

the variability between the $k$ values of the various dust samples at non-absorbing wavelengths above $600 \mathrm{~nm}$. As particle size and shape are very similar for all investigated dust probes, however, particle scattering should lead to a systematic bias in all mean $k$ data sets rather than introducing relative changes between them. Thus, we strongly assume that the difference in the background absorption values is indeed an intrinsic property of the dust samples. In order to verify this hypothesis, we compare the SOAP retrievals with those from the four wavelengths photo acoustic spectrometer $(4 \lambda$ PAS) that has no cross sensitivity to particle scattering.

Such a comparison is shown in Fig. 11 for the SAMUM B2, Cairo 2, and Burkina Faso soil samples. For the

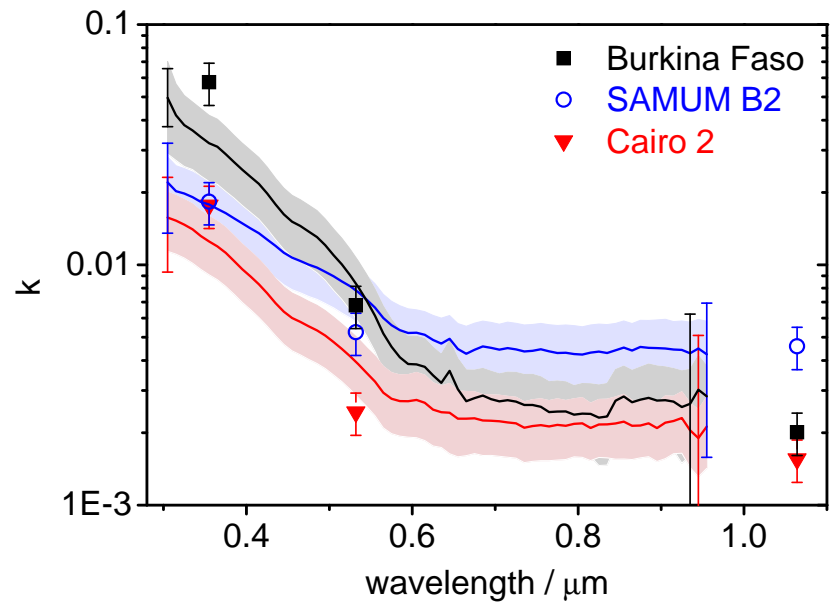

Fig. 11. Comparison of the $k$ retrievals from the SOAP (lines) and $4 \lambda$-PAS (symbols) absorption measurements for dispersed dust particles from the Burkina Faso, SAMUM B2, and Cairo 2 soil samples. Shaded areas and error bars denote various uncertainty estimates that are discussed in detail in the text.

SOAP data, two different error estimates were applied. The shaded areas represent the standard errors of the means from Fig. 10, added by an uncertainty of $9 \%$ for the appropriate shape representation of the dust grains and an additional uncertainty of $13 \%$ reflecting the variability of the retrieval results with the choice for $n$ (Sect. 4.3.3). The explicit error bars plotted at the low and the high wavelength end of the SOAP retrievals ( 305 and $955 \mathrm{~nm}$ ) for $k$ reflect the spread in the retrieval results when applying the formula from Müller et al. (2011) to calculate the uncertainty in the absorption measurements, $\Delta \sigma_{\mathrm{abs}}$, due to particle scattering. In the latter case, as discussed above, the prominent difference of $k$ between the Burkina Faso and the other two dust samples at UV wavelengths exceeds the range of uncertainty whereas the variations in the background absorption values are much smaller than the estimated maximum uncertainties. The important outcome from the comparison shown in Fig. 11 is that also the $4 \lambda$-PAS retrievals for $k$ at $1064 \mathrm{~nm}$ reveal the same trend in the background absorption levels at $\lambda>600 \mathrm{~nm}$, i.e. $k($ SAMUM B2) $\gg k$ (Burkina Faso $)>k($ Cairo 2$)$. For the photo acoustic data, an uncertainty of $\pm 20 \%$ was assumed. This reflects maximum deviations from reference instruments which were observed in recent test measurements with soot particles (Ajtai et al., 2010). The variations in the retrievals for $k$ at $1064 \mathrm{~nm}$ clearly exceed this uncertainty level. The spread in the $k$ retrievals for $\lambda>600 \mathrm{~nm}$ therefore indeed represents the actual variability of the background absorption level of the various dispersed Saharan soil samples. Considering the error estimate of the SOAP data represented by the shaded areas, the deviations between the SOAP and photo-acoustic retrievals for $k$ at 955 and $1064 \mathrm{~nm}$, respectively, are smaller than the combined uncertainty range of both methods. 
Table 5. Retrieval results for the imaginary part of the complex refractive index, $k$, at selected wavelengths, $\lambda$, for the five investigated Saharan dust samples. The tabulated data are mean $k$ values from a set of individual measurements with SOAP. As explained in the text, the errors $\Delta k$ account for the precision of the SOAP measurements as well as for the uncertainties associated with the retrieval scheme.

\begin{tabular}{|c|c|c|c|c|c|c|c|c|c|c|}
\hline \multirow[t]{2}{*}{$\lambda \mathrm{nm}$} & \multicolumn{2}{|c|}{ Burkina Faso } & \multicolumn{2}{|c|}{ Cairo 2} & \multicolumn{2}{|c|}{ SAMUM B1 } & \multicolumn{2}{|c|}{ SAMUM B2 } & \multicolumn{2}{|c|}{ SAMUM B3 } \\
\hline & $k$ & $\Delta k$ & $k$ & $\Delta k$ & $k$ & $\Delta k$ & $k$ & $\Delta k$ & $k$ & $\Delta k$ \\
\hline 305 & 0.0495 & 0.0206 & 0.0157 & 0.0043 & 0.0164 & 0.0058 & 0.0220 & 0.0061 & 0.0168 & 0.0048 \\
\hline 355 & 0.0321 & 0.0098 & 0.0125 & 0.0034 & 0.0142 & 0.0046 & 0.0178 & 0.0048 & 0.0152 & 0.0043 \\
\hline 405 & 0.0233 & 0.0067 & 0.0089 & 0.0024 & 0.0117 & 0.0037 & 0.0142 & 0.0038 & 0.0119 & 0.0033 \\
\hline 455 & 0.0151 & 0.0043 & 0.0060 & 0.0016 & 0.0093 & 0.0028 & 0.0107 & 0.0028 & 0.0087 & 0.0024 \\
\hline 505 & 0.0110 & 0.0031 & 0.0048 & 0.0013 & 0.0081 & 0.0024 & 0.0090 & 0.0023 & 0.0071 & 0.0020 \\
\hline 555 & 0.0061 & 0.0018 & 0.0033 & 0.0009 & 0.0065 & 0.0019 & 0.0066 & 0.0017 & 0.0049 & 0.0014 \\
\hline 605 & 0.0039 & 0.0012 & 0.0027 & 0.0008 & 0.0056 & 0.0015 & 0.0052 & 0.0013 & 0.0035 & 0.0010 \\
\hline 655 & 0.0030 & 0.0010 & 0.0023 & 0.0007 & 0.0051 & 0.0014 & 0.0045 & 0.0012 & 0.0031 & 0.0009 \\
\hline 705 & 0.0027 & 0.0008 & 0.0022 & 0.0006 & 0.0052 & 0.0015 & 0.0044 & 0.0012 & 0.0030 & 0.0008 \\
\hline 755 & 0.0026 & 0.0009 & 0.0022 & 0.0006 & 0.0053 & 0.0014 & 0.0045 & 0.0013 & 0.0029 & 0.0008 \\
\hline 805 & 0.0024 & 0.0008 & 0.0022 & 0.0006 & 0.0053 & 0.0014 & 0.0042 & 0.0013 & 0.0029 & 0.0008 \\
\hline 855 & 0.0028 & 0.0009 & 0.0022 & 0.0007 & 0.0054 & 0.0015 & 0.0045 & 0.0013 & 0.0031 & 0.0009 \\
\hline 905 & 0.0027 & 0.0010 & 0.0022 & 0.0006 & 0.0056 & 0.0015 & 0.0045 & 0.0014 & 0.0032 & 0.0010 \\
\hline 955 & 0.0028 & 0.0009 & 0.0021 & 0.0007 & 0.0057 & 0.0016 & 0.0042 & 0.0016 & 0.0030 & 0.0008 \\
\hline
\end{tabular}

At 355 and $532 \mathrm{~nm}$, there seems to be a systematic deviation between the SOAP and $4 \lambda$-PAS retrievals for $k$, namely lower $k$ values from the photo acoustic data compared to SOAP at $532 \mathrm{~nm}$ whereas the opposite behaviour is observed at $355 \mathrm{~nm}$. A potential reason for systematic deviations between SOAP and $4 \lambda$-PAS at specific wavelengths might be related to uncertainties in the calibration of the photoacoustic instrument because it is composed of four individual detection cells (one for each wavelength), and for each of them, an individual cell constant has to be determined (Ajtai et al., 2010). This issue will be explored in future inter-comparison measurements. However, we note that also the deviations between SOAP and $4 \lambda$-PAS retrievals at these two wavelengths are in most cases smaller than the combined uncertainty range of both methods. Table 5 contains a compilation of the retrieved $k$ values from SOAP at some selected wavelengths. The tabulated errors, $\Delta k$, represent the shaded areas from Fig. 11, thus include the precision of the SOAP measurements and the uncertainties associated with the retrieval scheme. As shown by the comparison with the $4 \lambda$-PAS retrievals, the strict application of the Müller et al. (2011) expression for $\Delta \sigma_{\text {abs }}$ would largely overestimate the uncertainties of $k$ at $\lambda>600 \mathrm{~nm}$. In the next section, we investigate how accurately the retrieved $k$ spectra can be mimicked by employing mixing rule approaches using the hematite contents derived from the single particle analyses of the mineralogical composition as input. We further compare our deduced $k$ data sets to those recently published in the literature.

\subsection{Discussion: comparison with literature data and mixing-rule approaches}

When comparing our retrieved $k$ data sets with previous literature results, it should be kept in mind that our data represent effective values for entire dust particle populations that were obtained by dispersing various soil samples from specific geographic locations. This is because our T-matrix model has treated the particles as being homogeneous although the exemplarily shown TEM image in Fig. 5 underlines the high complexity of the internal particle structure. We also assumed that the refractive index is size-independent for a given measurement. The comparison with other laboratory studies where e.g. powder samples were employed to retrieve $k$ by diffuse reflectance (Sokolik et al., 1993) only has limited significance because our mineralogical analyses have clearly evidenced the difference in the composition between the bulk samples (20-75 $\mu \mathrm{m}$ sieved fraction) and the air-borne particles. Two major uncertainties arise when comparing our $k$ spectra to those retrieved during field campaigns like SAMUM-1, even if the latter took place in the source region where some of our dust samples were collected. First, the dispersion of a sieved fraction of the soil samples with the inclusion of impaction stages will not entirely reproduce the size distribution of the atmospheric dust load. Secondly, even for field measurements in a source region of mineral dust, a correction for soot is necessary to infer the refractive indices of the pure dust mode because strongly absorbing soot particles, even if only present in small amounts, might significantly contribute to the $k$ value of the total aerosol (Müller et al., 2009). This soot correction, however, is affected by a high degree of uncertainty. 


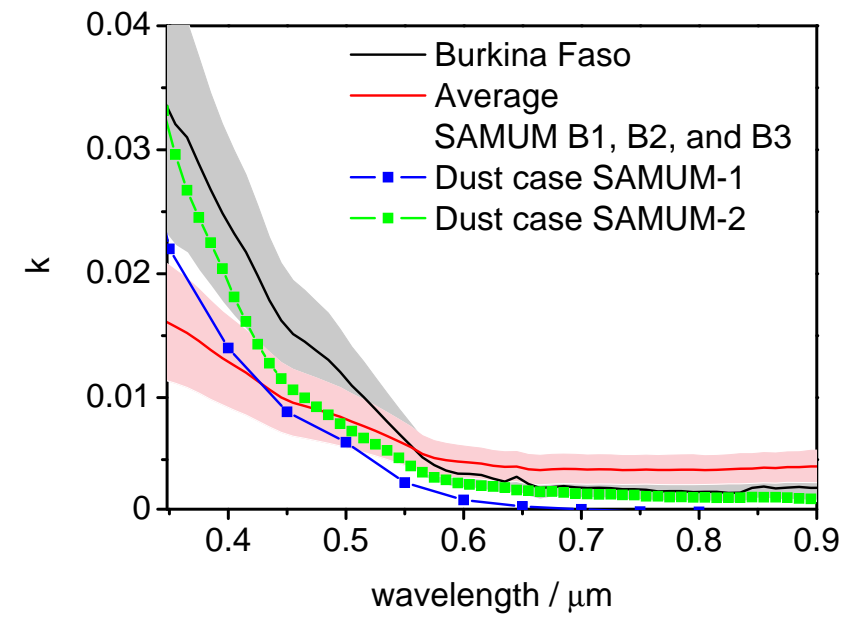

Fig. 12. Retrieved $k$ spectrum for the Burkina Faso dust probe and averaged $k$ spectrum for the three SAMUM B1, B2, and B3 dust samples from this study (the shaded areas represent the errors from Table 5) in comparison with imaginary parts of refractive indices derived during the SAMUM-1 and SAMUM-2 field campaigns for typical dust cases; see Fig. 8 in Müller et al. (2011).

Figure 1 in Sokolik et al. (1993) shows a collection of $k$ spectra for dust samples from different geographical regions which were deduced by various methods. The longwavelength background absorption level at $1000 \mathrm{~nm}$ varies between about $k=0.003$ and 0.007 . Towards UV wavelengths, the reported imaginary indices increase to about $k=0.008-0.025$ at $300 \mathrm{~nm}$. Our own data for the Cairo 2 and the three SAMUM dust samples accurately fit into these $k$ regimes whereas the Burkina Faso dust sample with the highest hematite content obviously represents an extreme case, featuring $k$ values towards UV wavelengths which are higher than all data shown in the Sokolik et al. (1993) collection. Retrievals of $k$ from the worldwide AERONET network for typical dust sites show much lower imaginary refractive indices with $k$ not exceeding 0.003 at $440 \mathrm{~nm}$ (Dubovik et al., 2002a). Balkanski et al. (2007) have addressed this difference and argued that dust absorption at visible wavelengths might be lower than previously thought because mixing rule calculations with a hematite content of $1.5 \mathrm{vol} \%$, supposed to be representative for median dust absorption, showed a very good agreement with the AERONET measurements. As will be discussed later in this section, however, the results of these calculations will strongly depend on which tabulated values for the hematite refractive index are employed. In Fig. 12, we show our retrieved $k$ spectrum for the Burkina Faso dust sample and the averaged $k$ data set for the three SAMUM dust samples in comparison with spectra retrieved during the SAMUM-1 and SAMUM-2 field campaigns for typical dust cases. The latter data were taken from Fig. 8 in Müller et al. (2011). Given the limitations of such a comparison as discussed above, the $k$ data set deduced during the SAMUM-1 field campaign and representing the atmospheric dust load shows a reasonable agreement with the averaged refractive indices of the three dispersed soil samples collected in the source region. The SAMUM-2 dust case shows higher $k$ values than SAMUM-1. The aerosol probed during SAMUM2 , however, was transported over long distances to the Cape Verde islands and represents a complex mixture of dust and other compounds (soot, sulphate, sea-salt; Kandler et al., 2011; Lieke et al., 2011) where it is not possible to infer the pure dust contribution (Müller et al., 2011). The Burkina Faso $k$ data set can obviously be regarded as the upper limit of dust absorption at wavelengths below about $550 \mathrm{~nm}$.

The single particle analyses of the dispersed SAMUM B3, SAMUM B1, and Burkina Faso soil samples have yielded hematite volume abundances between 1.1 and $2.7 \%$. The approximately doubled hematite content of the Burkina Faso compared to the SAMUM dust particles is nicely reflected by the two-fold difference in their absorption potential below $500 \mathrm{~nm}$ (Fig. 12). Note again that based on the bulk analyses discussed in Sect. 3.3.1, a much larger difference would have been predicted (Table 3). Using a mineralogical database, Balkanski et al. (2007) have identified hematite volume abundances of 0.9 and $2.7 \%$ as low and high hematite contents of mineral aerosol, respectively, arguing that this range is also in accordance with estimates of iron oxides in dust samples by Lafon et al. (2004) and Linke et al. (2006). We are therefore confident that the variety of dust samples that were probed in our study reasonably brackets the range of hematite amounts in atmospheric dust aerosols.

In the remaining part of the discussion, we want to compare our retrieved $k$ data sets to those calculated with various mixing rule approaches for the hematite contents deduced from the single particle analyses. Before showing our results, we want to emphasise that we consider these mixing rule calculations not as a stringent test for verification of our retrieval results. Instead, it is rather a sensitivity study for the applicability of the mixing rule approach to reproduce effective refractive index data sets of mineral dust aerosols because we identify at least three major uncertainties that are associated with this method:

i. The hematite volume abundance that is employed in the mixing rule calculations can only be approximately inferred from the SEM analyses because an average value for the ratio hematite to total iron has to be assumed (see Sect. 3.3.2). Also the amount of another potentially light absorbing mineral, namely goethite, remains unspecified. Based on the optical properties measured by Bedidi and Cervelle (1993), however, goethite has a clearly lower absorption potential than hematite at wavelengths below $600 \mathrm{~nm}$.

ii. The tabulated complex refractive indices for hematite show a huge variation; see e.g. Table 1 in Meland et al. (2011). At wavelengths below $600 \mathrm{~nm}$, the $k$ values from Bedidi and Cervelle (1993) which were 
employed in the mixing rule calculations by Balkanski et al. (2007) are more than a factor of two smaller than those used by Sokolik and Toon (1999), adapted from an earlier work by Querry (1987). Meland et al. (2011) have observed best agreement between theoretical scattering simulations and experimental scattering data for hematite aerosol particles at wavelengths below $600 \mathrm{~nm}$ for simulations based on the Querry (1987) data. As in Kandler et al. (2009), we therefore used the Querry (1987) refractive indices for our mixing rule calculations. An averaged data set of refractive indices was calculated from the $e$-ray and $o$-ray optical constants with a $1 / 3$ to $2 / 3$ weighting.

iii. A simplified mixing rule model that, e.g. applies to an entirely randomly inhomogeneous medium like the Bruggeman approximation (Bohren and Huffman, 1983), will only be a rough representation of the complex internal structure of a dust particle (Fig. 5). Similar to Sokolik and Toon (1999), we have employed the volume mean approximation as well as two effective medium theories, the Maxwell-Garnett and the Bruggeman approximations in our simulations. Sokolik and Toon (1999) have shown that both effective medium theories give similar results for the imaginary indices of two-component mixtures of quartz and hematite whereas maximum deviations of more than $80 \%$ are obtained between the computed $k$ values from the volume mean and the Bruggeman approximation for aggregates made of $99 \%$ quartz and $1 \%$ hematite at a wavelength of $500 \mathrm{~nm}$.

Since hematite is the only absorbing substance in the fivecomponent model by Kandler et al. (2009) (see Table 3 therein) and because the real parts of the complex refractive index for the other four components are rather similar, we have transferred the results for the dust particle composition shown in Table 4 into a two-component model consisting of hematite and a general non-absorbing compound. For the latter, we have summed up the volume fractions of the "average silicate", "quartz", "calcite", and "sulphate" components and assumed a real refractive index that linearly increases from 1.53 at $1000 \mathrm{~nm}$ to 1.58 at $300 \mathrm{~nm}$. In the Maxwell-Garnett approximation, the non-absorbing component is treated as the homogeneous matrix where spherical hematite inclusions are embedded. In the Bruggeman approximation, both components are treated symmetrically. We employed the formulae given in Sokolik and Toon (1999) for our calculations. Figure 13 compares our retrieved $k$ spectra for the Burkina Faso, SAMUM B1, and SAMUM B3 dust particles with those computed using the two effective medium theories and the volume mean approximation. As reported by Sokolik and Toon (1999), the computed $k$ values from the Maxwell-Garnett and Bruggeman approximations closely agree whereas the results from the volume mean approximation are much higher with maximum deviations of
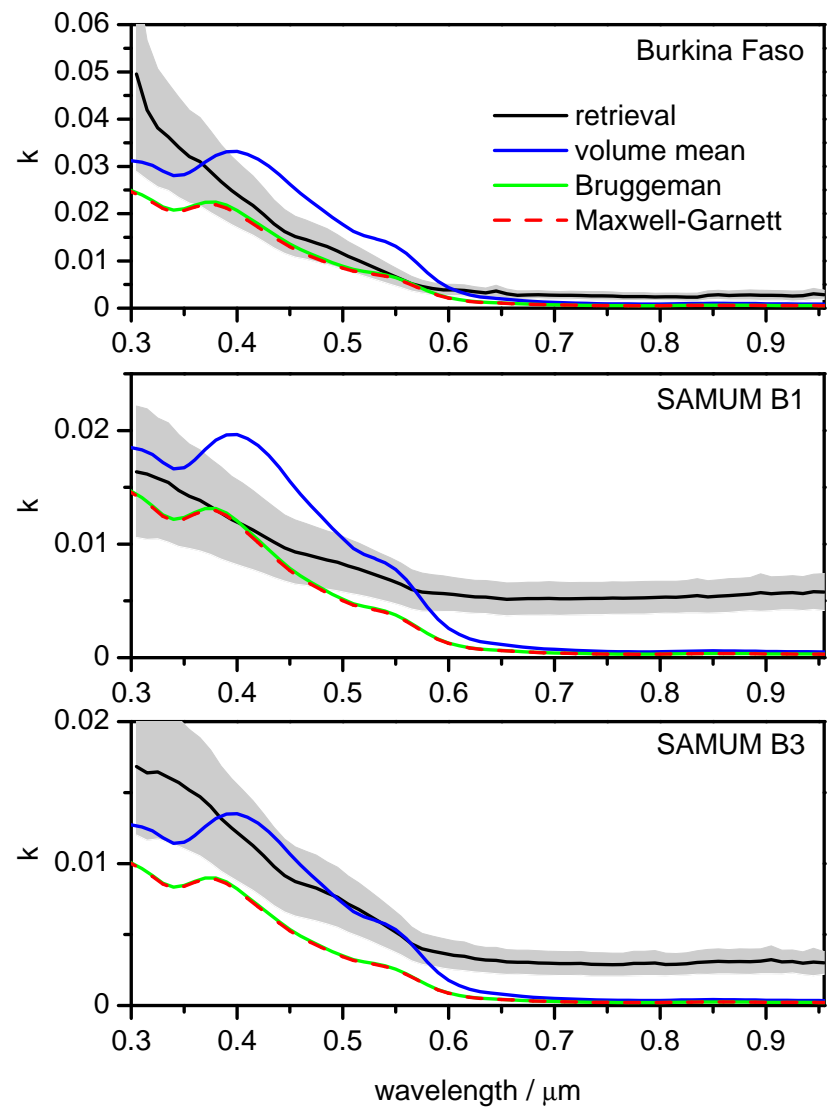

Fig. 13. Comparison of the retrieved $k$ spectra for the dispersed Burkina Faso, SAMUM B1, and SAMUM B3 soil samples (the shaded areas represent the errors from Table 5) with those computed with various mixing rule approaches (volume mean, Bruggeman, and Maxwell-Garnett approximation; see Sokolik and Toon, 1999), employing the hematite volume abundances derived from the single particle analyses of the mineralogical composition (Table 4). See text for details.

almost $100 \%$ at $500 \mathrm{~nm}$. The mixing rule calculations do not reproduce the retrieved background absorption level at wavelengths larger than $600 \mathrm{~nm}$, as particularly evident for the SAMUM B1 and B3 dust particles. On the one hand, some mineral components of the dust samples apart from hematite might feature such a low absorption background that is not properly described by the tabulated refractive index data. On the other, the dust samples with the elevated background absorption level might contain an additional, non-mineral compound that shows a spectrally flat absorption (Müller et al., 2011).

Between 600 and $400 \mathrm{~nm}$, the retrieved $k$ values are within the regime spanned by the volume mean and the effective medium approximations. Towards the UV regime below $\lambda=400 \mathrm{~nm}$, the increase of $k$ in the mixing rule calculations starts to level off whereas the retrieved $k$ values, in particular for the Burkina Faso and the SAMUM B3 sample, continue to increase in the retrieved data sets. A variety 
of explanations could account for this behaviour, including a higher uncertainty of the SOAP measurements towards UV wavelengths, errors in the tabulated refractive indices for hematite, or the onset of absorption by other mineral constituents in this spectral regime. Note that our computed $k$ values are much higher than those from the mixing rule calculations by Balkanski et al. (2007) (see Figs. 3 and 4 therein) although similar volume fractions of hematite were employed. This difference is solely related to the variations in the tabulated refractive indices for hematite.

\section{Summary}

Five different Saharan soil samples of variable mineralogical composition were dispersed into an aerosol chamber yielding number size distributions with median dust particle diameters of typically $0.3-0.4 \mu \mathrm{m}$ and upper particle diameters in the range from 2 to $4 \mu \mathrm{m}$, depending on the number of impaction stages that were used during aerosol generation. The extinction and absorption coefficients as well as the number size distribution of the dust particles were simultaneously measured with various techniques to retrieve their complex refractive indices at wavelengths between 305 and $955 \mathrm{~nm}$ with an inversion scheme based on a spheroidal dust model. Since previous literature studies have revealed that the real part of the complex refractive index of dust aerosols is rather constant over the considered spectral range, its value was fixed to 1.53. The extinction spectra were used as reference measurements to optimise the simultaneously recorded number size distributions of the dust particles. Thereby, the inherent uncertainties associated with the sizing of dust which are caused, e.g. by corrections needed to account for the asphericity of the particles, could be reduced. We have shown that computations for elongated dust spheroids of aspect ratio 0.25 best fitted the measured extinction spectra whereas calculations for dust spheres did not accurately reproduce the observed spectral habitus. The optimised number size distributions were then used to derive the effective, wavelengthresolved imaginary parts of the complex refractive index of the dust aerosols from the measured absorption coefficients. This retrieval step proved to be almost insensitive to the shape of the dust particles.

The retrieved data sets of the imaginary part of the complex refractive index were analysed in terms of the hematite content of the dust aerosols because this mineral features the largest absorption potential at visible and UV wavelengths. The hematite content was inferred from single particle analyses using electron microscopy. These analyses proved to be indispensable because we have found that the mineralogical composition of the airborne particles clearly deviated from the bulk composition of the soil samples. The volume fraction of hematite in the dust aerosols varied between 1.1 and $2.7 \%$ and is in good agreement with the range of hematite contents that are assumed to be representative of atmospheric dust aerosols. Therefore, our retrieved $k$ data sets are valuable to constrain the range of variability of the absorption potential of airborne dust particles.

At wavelengths larger than $600 \mathrm{~nm}$, i.e. above the onset of dust absorption due to hematite, the retrieved $k$ values varied between 0.003 and 0.005 . At $505 \mathrm{~nm}, k$ increased to $0.005-$ 0.011 and a range of $k$ values between 0.016 and 0.050 was observed in the UV regime at $305 \mathrm{~nm}$. The highest $k$ values, retrieved for a reddish brown coloured dust sample from Burkina Faso, were considered as an upper limit for the absorption potential of atmospheric dust aerosols. The averaged $k$ data set of three yellow brown coloured, dispersed soil samples that were collected in southern Morocco during the SAMUM-1 field campaign showed a good agreement with the $k$ values deduced from the field measurements for a typical dust case. In a sensitivity study, we have investigated how accurately the retrieved $k$ data sets could be mimicked by mixing rule approximations employing the experimentally determined hematite contents as input. The results from these calculations are in qualitative agreement with our retrieved $k$ values but feature a huge variation depending on which model is used to describe the mixing state of the mineral aerosols and which tabulated refractive index data set for hematite is employed.

\section{Appendix A}

\section{Computational details}

\section{A1 Computational methods}

We have calculated the extinction and absorption cross sections of the spheroids with the extended precision FORTRAN T-matrix code for randomly oriented particles by Mishchenko and Travis (1998) up to size parameters where stable performance was guaranteed. For large deviations from the spherical shape, the T-matrix computations became non-convergent before the largest considered size parameter of $x_{\mathrm{v}}=50$ was reached. Beside $\varepsilon$, this convergence limit also depends on the magnitude of the real and imaginary part of the complex refractive index (Mishchenko and Travis, 1998). Above the convergence point of the T-matrix calculations, we have continued our computations with a ray-tracing model including diffraction of light incident on the particles' projected area (Macke et al., 1996). In the framework of the geometric optics approximation with the allowance for diffraction, the extinction efficiency $Q_{\text {ext }}$ (extinction cross section, $C_{\text {ext }}$, divided through the average cross-sectional area of the particles) is equal to 2 and the value for the absorption efficiency, $Q_{\text {abs }}$, does not exceed unity. In reality, however, the limit $Q_{\text {ext }}=2$ is only reached for size parameters well above our considered size range and absorption resonances might occur with $Q_{\mathrm{abs}}>1$ (Baran et al., 2001). The differences between the true extinction and absorption efficiencies $Q_{\text {ext }}$ 

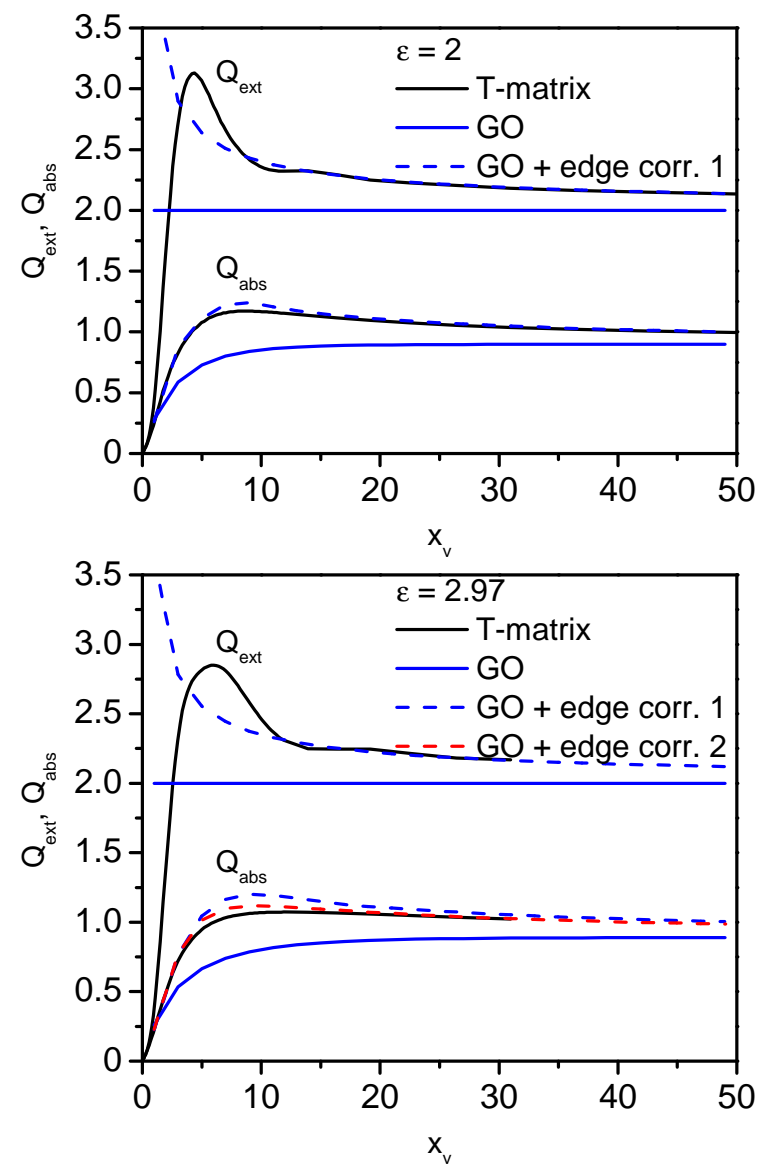

Fig. A1. Computed extinction, $Q_{\text {ext }}$, and absorption, $Q_{\text {abs }}$, efficiencies for randomly oriented oblate spheroids with an aspect ratio, $\varepsilon$, of 2 (top panel) and 2.97 (bottom panel) as a function of the (equalvolume sphere) size parameter $x_{\mathrm{v}}$. The employed complex refractive index was $1.5+0.1 \mathrm{i}$. The black lines denote calculations with the T-matrix method and the blue lines computations with the ray tracing method including diffraction (GO: geometric optics). The dashed blue and red lines represent corrected geometric optics results including an edge correction as outlined in the text.

and $Q_{\text {abs }}$ calculated with the T-matrix method and their counterparts calculated in the geometric optics approximation are called the edge contributions (Baran and Havemann, 1999; Fournier and Evans, 1991; Kokhanovsky and Zege, 1995; Yang et al., 2007). The edge contribution to the extinction efficiency for randomly oriented spheroids was calculated according to the approximations by Fournier and Evans (1991). Similar to Yang et al. (2007), the edge contribution to the absorption efficiency of a spheroid of diameter $d_{\mathrm{v}}$ was in the first step approximated to be equal to that of an equal-volume sphere. The latter quantity was calculated as the difference between the true absorption efficiency calculated with Mie theory and the geometric optics result.
Two examples of the applied edge corrections are displayed in Fig. A1. In the top panel, we show an example where the T-matrix computations were convergent over the complete range of size parameters (oblate spheroids with $\varepsilon=2$, complex refractive index $=1.5+0.1$ i) in order to assess the accuracy of the edge correction. Whereas the pure geometric optics results for the extinction and absorption efficiencies reveal clear deviations from the T-matrix values for the reasons outlined in the preceding paragraph, the addition of the edge contribution leads to a very good agreement with the T-matrix result for size parameters larger than about 15 . In the second example shown in the bottom panel, we have increased $\varepsilon$ to 2.97. The convergence limit of the T-matrix computations is at about $x_{\mathrm{v}}=31$. For the extinction efficiency, an accurate extension of the truncated T-matrix results is obtained by including the edge contribution. The absorption efficiency at the threshold size parameter of $x_{\mathrm{v}}=31$, however, is slightly overestimated when adding the edge contribution of an equal-volume sphere to the geometric optics result (dashed blue line). A better extension of the $Q_{\text {abs }}$ curve is obtained when equalling the edge contribution to that of an equal-volume spheroid of $\varepsilon=2$ (dashed red line, obtained as difference from the true $Q_{\text {abs }}$ calculated by the T-matrix method and the geometric optics result). In the second step, we have therefore computed the edge contribution to $Q_{\text {abs }}$ for prolate and oblate spheroids with the largest asphericity for which stable T-matrix results could be obtained over the complete range of size parameters. These values were then used to improve the geometric optics results of $Q_{\text {abs }}$ for spheroids of higher asphericity at size parameters where the T-matrix calculations did not converge.

\section{A2 Shape dependency of the computed extinction and absorption cross sections}

In Fig. A2, we have compiled selected computational results from the database to underline the shape dependency of the optical cross sections of the randomly oriented spheroids. The top panel shows the extinction cross sections as a function of the particles' equal-volume sphere diameter, $d_{\mathrm{v}}$, at a wavelength of $500 \mathrm{~nm}$ for a complex refractive index of $1.5+0.014 \mathrm{i}$. A set of curves for all considered aspect ratios is shown, with selected shapes highlighted by coloured lines. Up to a $d_{\mathrm{v}}$ of about $0.7 \mu \mathrm{m}$, the spread of the individual traces is low. As evident from the insert, an increasing degree of particle asphericity leads to a slight decrease in the extinction cross sections. As an example, $C_{\text {ext }}$ for $0.5 \mu \mathrm{m}$ sized spheroids of aspect ratio $\varepsilon=0.25$ (red line) is lowered by about $10 \%$ compared to spheres (green line). Larger deviations from the results for spheres in this size regime are only expected for particles with extreme aspect ratios, e.g. needle- and plate-like particles (Zakharova and Mishchenko, 2000).

Above $0.7 \mu \mathrm{m}$, the results for the extinction cross sections of the various spheroidal particle shapes start to diverge 

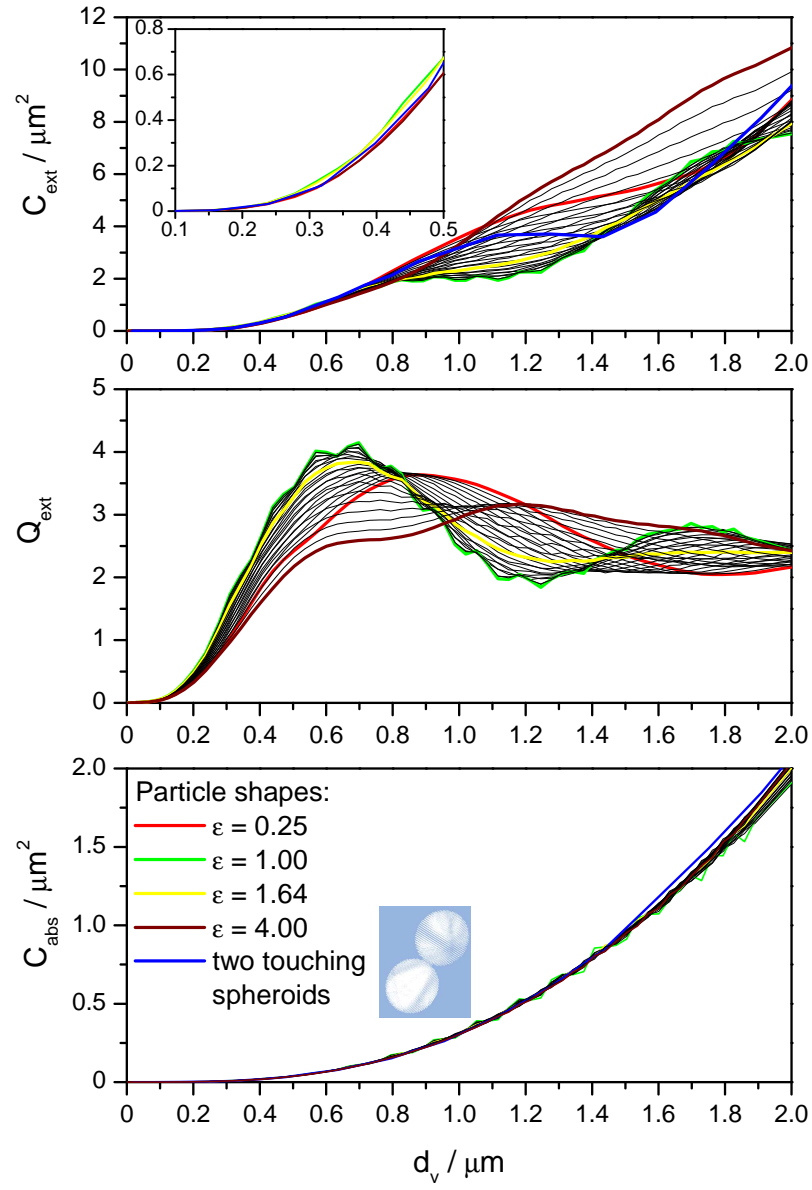

Fig. A2. Shape dependency of the optical cross sections and efficiencies of randomly oriented spheroidal particles. All results hold for a wavelength of $500 \mathrm{~nm}$ and a complex refractive index of $1.5+0.014 \mathrm{i}$. Top panel: extinction cross sections for all 29 considered particle shapes between $\varepsilon=0.25$ and $\varepsilon=4.0$. Results of selected shapes are highlighted by coloured curves, as denoted in the legend of the bottom panel. The blue trace shows the additional result for an aggregate particle composed of two touching spheroids. The insert shows the results for the coloured curves in an expanded view for $d_{\mathrm{V}}$ from 0.1 to $0.5 \mu \mathrm{m}$. Middle panel: same set of calculations as in the top panel, now expressed as extinction efficiency. Bottom panel: absorption cross sections for all 29 considered spheroidal particle as well as the aggregate particle.

because we enter the size range where extinction is governed by the interference structure, i.e. series of extinction minima and maxima caused by interference of incident and forwardscattered light (Bohren and Huffman, 1983). The interference structure can be better seen when plotting the extinction efficiencies as a function of $d_{\mathrm{v}}$, as shown in the middle panel of Fig. A2. For slightly aspherical spheroids (e.g. $\varepsilon=1.64$, yellow line), the regular series of extinction minima and maxima observed for spheres (green line) is still conserved. A higher degree of asphericity, however, induces a strong distortion of these regular oscillations. Oblate spheroids of aspect ratio $\varepsilon=4$ (brown line), for example, show a first extinc- tion efficiency maximum at $d_{\mathrm{v}}=1.2 \mu \mathrm{m}$ whereas for spheres this particle size corresponds to the first extinction minimum after having already surpassed the first extinction maximum at $d_{\mathrm{v}}=0.7 \mu \mathrm{m}$. The extinction cross section (top panel) of $1.2 \mu \mathrm{m}$ sized $\varepsilon=4$ spheroids is thereby more than a factor of two higher than that of spheres. These pronounced shape dependent variations in $C_{\text {ext }}$ are essential in the discussion of our inversion scheme in Sect. 4.3.2 because, depending on the wavelength, a significant part of the dust particle number size distributions may extend into the size range that is dominated by the interference structure.

In addition to the spheroid computations, we have performed a single test calculation of $C_{\mathrm{ext}}$ and $C_{\mathrm{abs}}$ for an aggregate-like particle that might be a better representation for the habit of irregularly formed natural dust grains. The aggregate particle was modelled as two touching spheroids with individual aspect ratios of 1.07 and 1.20. The two spheroids have a volume ratio of 1.12 and an angle between their individual rotational axes of $45^{\circ}$. The optical cross sections of the aggregate particle in random orientation were computed with the discrete dipole approximation (DDA), using the DDSCAT 6.0 FORTRAN software package (Draine and Flatau, 1994). The trace for $C_{\text {ext }}$ of the two touching ellipsoids, shown as blue line in the top panel, is up to a $d_{\mathrm{v}}$ of about $1.1 \mu \mathrm{m}$ very similar to that of the most elongated spheroid ( $\varepsilon=0.25$, red line), a finding that is also discussed in Sect. 4.3.2.

The bottom panel of Fig. A2 displays the shape dependent absorption cross sections for the 29 considered spheroidal particle shapes as well as for the aggregate-like particle. For equal-volume sphere diameters up to about $1.5 \mu \mathrm{m}$, the individual traces coincide, meaning that $C_{\mathrm{abs}}$ is proportional to the particle volume and does not show any variations with increasing asphericity as long as $d_{\mathrm{v}}$ is kept constant. For all dust experiments where two impaction stages were used during aerosol generation, almost the entire particle volume concentration is governed by particles of $d_{\mathrm{v}}$ less than $1.5 \mu \mathrm{m}$ (Fig. 2). Hence, shape effects can be neglected when retrieving the imaginary part of the complex refractive index from the absorption spectra. Above $1.5 \mu \mathrm{m}$, the individual traces for $C_{\text {abs }}$ start to diverge slightly, with up to $10 \%$ higher values for the most aspherical spheroidal shapes compared to spheres at $d_{\mathrm{v}}=2.0$. This is an indication that $C_{\mathrm{abs}}$ becomes sensitive to the surface area of the particles (Bohren and Huffman, 1983). More elongated or flattened spheroids with $\varepsilon=0.25$ or $\varepsilon=4$ start to reveal slightly higher absorption cross sections compared to spheres or more compact spheroids because the surface area of spheroids with a given $d_{\mathrm{v}}$ increases with increasing asphericity. As discussed in Sect. 4.3.3, this effect introduces a small uncertainty to the retrieval results for the imaginary part of the complex refractive index for those experiments where only a single impaction stage was used. Here, particles of $d_{\mathrm{v}}$ larger than $1.5 \mu \mathrm{m}$ significantly contribute to the total dust volume concentration. 
Acknowledgements. This research was funded by the HelmholtzGemeinschaft Deutscher Forschungszentren as part of the program "Atmosphere and Climate". We thank C. Adelhelm (Institute for Applied Materials - Applied Materials Physics, IAM-AWP, Karlsruhe Institute of Technology) for the analyses of the elemental composition of the soil samples. A special thank is addressed to L. Schütz (Institute for Atmospheric Physics, University of Mainz) and M. Kohler (Institute for Meteorology and Climate Research - Troposphere Research, IMK-TRO, Karlsruhe Institute of Technology) for providing the desert dust samples. We acknowledge a partial funding by the Deutsche Forschungsgemeinschaft in the frame of the SAMUM research group (FOR 539).

Edited by: M. Krämer

\section{References}

Ajtai, T., Filep, A., Schnaiter, M., Linke, C., Vragel, M., Bozoki, Z., Szabo, G., and Leisner, T.: A novel multi-wavelength photoacoustic spectrometer for the measurement of the UV-visNIR spectral absorption coefficient of atmospheric aerosols, J. Aerosol Sci., 41, 1020-1029, 2010.

Alfaro, S. C., Lafon, S., Rajot, J. L., Formenti, P., Gaudichet, A., and Maille, M.: Iron oxides and light absorption by pure desert dust: An experimental study, J. Geophys. Res.-Atmos., 109, D08208, doi:10.1029/2003JD004374, 2004.

Balkanski, Y., Schulz, M., Claquin, T., and Guibert, S.: Reevaluation of Mineral aerosol radiative forcings suggests a better agreement with satellite and AERONET data, Atmos. Chem. Phys., 7, 81-95, doi:10.5194/acp-7-81-2007, 2007.

Baran, A. J. and Havemann, S.: Rapid computation of the optical properties of hexagonal columns using complex angular momentum theory, J. Quant. Spectrosc. Ra., 63, 499-519, 1999.

Baran, A. J., Francis, P. N., Havemann, S., and Yang, P.: A study of the absorption and extinction properties of hexagonal ice columns and plates in random and preferred orientation, using exact T-matrix theory and aircraft observations of cirrus, J. Quant. Spectrosc. Ra., 70, 505-518, 2001.

Bedidi, A. and Cervelle, B.: Light-Scattering by Spherical-Particles with Hematite and Geothite-Like Optical-Properties - Effect of Water Impregnation, J. Geophys. Res.-Sol. Ea., 98, 1194111952, 1993.

Bohren, C. F. and Huffman, D. R.: Absorption and Scattering of Light by Small Particles, John Wiley \& Sons, Inc., New York, 1983.

Chung, F. H.: Quantitative Interpretation of X-Ray-Diffraction Patterns of Mixtures. 1. Matrix-Flushing Method for Quantitative Multicomponent Analysis, J. Appl. Crystallogr., 7, 519-525, 1974.

Claquin, T., Schulz, M., and Balkanski, Y. J.: Modeling the mineralogy of atmospheric dust sources, J. Geophys. Res.-Atmos., 104, 22243-22256, 1999.

Draine, B. T. and Flatau, P. J., Discrete-Dipole Approximation for Scattering Calculations, J. Opt. Soc. Am. A, 11, 1491-1499, 1994.

Dubovik, O., Holben, B., Eck, T. F., Smirnov, A., Kaufman, Y. J., King, M. D., Tanre, D., and Slutsker, I., Variability of absorption and optical properties of key aerosol types observed in worldwide locations, J. Atmos. Sci., 59, 590-608, 2002a.
Dubovik, O., Holben, B. N., Lapyonok, T., Sinyuk, A., Mishchenko, M. I., Yang, P., and Slutsker, I.: Non-spherical aerosol retrieval method employing light scattering by spheroids, Geophys. Res. Lett., 29, 1415, doi:10.1029/2001GL014506, 2002b.

Dubovik, O., Sinyuk, A., Lapyonok, T., Holben, B. N., Mishchenko, M., Yang, P., Eck, T. F., Volten, H., Munoz, O., Veihelmann, B., van der Zande, W. J., Leon, J. F., Sorokin, M., and Slutsker, I.: Application of spheroid models to account for aerosol particle nonsphericity in remote sensing of desert dust, J. Geophys. Res.-Atmos., 111, D11208, doi:10.1029/2005JD006619, 2006.

Fournier, G. R. and Evans, B. T. N.: Approximation to Extinction Efficiency for Randomly Oriented Spheroids, Appl. Optics, 30, 2042-2048, 1991.

Hansen, J. E. and Travis, L. D.: Light-Scattering in Planetary Atmospheres, Space. Sci. Rev., 16, 527-610, 1974.

Hinds, W. C.: Aerosol Technology, John Wiley \& Sons, Inc., New York, 1999.

ICDD: Powder Diffraction File PDF-2, JCPDS - International Center for Diffraction Data, Newton Square, PA, USA, 2002.

Kandler, K., Benker, N., Bundke, U., Cuevas, E., Ebert, M., Knippertz, P., Rodriguez, S., Schutz, L., and Weinbruch, S.: Chemical composition and complex refractive index of Saharan Mineral Dust at Izana, Tenerife (Spain) derived by electron microscopy, Atmos. Environ., 41, 8058-8074, 2007.

Kandler, K., Schütz, L., Deutscher, C., Ebert, M., Hofmann, H., Jäckel, S., Jaenicke, R., Knippertz, P., Lieke, K., Massling, A., Petzold, A., Schladitz, A., Weinzierl, B., Wiedensohler, A., Zorn, S., and Weinbruch, S.: Size distribution, mass concentration, chemical and mineralogical composition and derived optical parameters of the boundary layer aerosol at Tinfou, Morocco, during SAMUM 2006, Tellus B, 61, 32-50, 2009.

Kandler, K., Lieke, K., Benker, N., Emmel, C., Küpper, M., MüllerEbert, D., Ebert, M., Scheuvens, D., Schladitz, A., Schütz, L., and Weinbruch, S.: Electron microscopy of particles collected at Praia, Cape Verde, during the Saharan Mineral Dust Experiment: particle chemistry, shape, mixing state and complex refractive index, Tellus B, 63, 475-496, 2011.

Karickhoff, S. W. and Bailey, G. W., Optical Absorption Spectra of Clay-Minerals, Clay Clay Miner., 21, 59-70, 1973.

Kokhanovsky, A. A. and Zege, E. P.: Local Optical-Parameters of Spherical Polydispersions - Simple Approximations, Appl. Optics, 34, 5513-5519, 1995.

Lafon, S., Rajot, J. L., Alfaro, S. C., and Gaudichet, A.: Quantification of iron oxides in desert aerosol, Atmos. Environ., 38, 1211-1218, 2004.

Lafon, S., Sokolik, I. N., Rajot, J. L., Caquineau, S., and Gaudichet, A.: Characterization of iron oxides in mineral dust aerosols: Implications for light absorption, J. Geophys. Res.-Atmos., 111, D21207, doi:10.1029/2005JD007016, 2006.

Lieke, K., Kandler, K., Scheuvens, D., Emmel, C., Von Glahn, C., Petzold, A., Weinzierl, B., Veira, A., Ebert, M., Weinbruch, S., and Schütz, L.: Particle chemical properties in the vertical column based on aircraft observations in the vicinity of Cape Verde Islands, Tellus B, 63, 497-511, 2011.

Linke, C., Möhler, O., Veres, A., Mohácsi, Á., Bozóki, Z., Szabó, G., and Schnaiter, M.: Optical properties and mineralogical composition of different Saharan mineral dust samples: a laboratory 
study, Atmos. Chem. Phys., 6, 3315-3323, doi:10.5194/acp-63315-2006, 2006.

Macke, A., Mueller, J., and Raschke, E.: Single scattering properties of atmospheric ice crystals, J. Atmos. Sci., 53, 2813-2825, 1996.

Meland, B., Kleiber, P. D., Grassian, V. H., and Young, M. A.: Visible light scattering study at 470,550, and $660 \mathrm{~nm}$ of components of mineral dust aerosol: Hematite and goethite, J. Quant. Spectrosc. Ra., 112, 1108-1118, 2011.

Meng, Z. K., Yang, P., Kattawar, G. W., Bi, L., Liou, K. N., and Laszlo, I.: Single-scattering properties of tri-axial ellipsoidal mineral dust aerosols: A database for application to radiative transfer calculations, J. Aerosol Sci., 41, 501-512, 2010.

Merikallio, S., Lindqvist, H., Nousiainen, T., and Kahnert, M.: Modelling light scattering by mineral dust using spheroids: assessment of applicability, Atmos. Chem. Phys., 11, 5347-5363, doi:10.5194/acp-11-5347-2011, 2011.

Mishchenko, M. I. and Travis, L. D.: Capabilities and limitations of a current FORTRAN implementation of the T-matrix method for randomly oriented, rotationally symmetric scatterers, J. Quant. Spectrosc. Ra., 60, 309-324, 1998.

Mishchenko, M. I., Travis, L. D., Kahn, R. A., and West, R. A.: Modeling phase functions for dustlike tropospheric aerosols using a shape mixture of randomly oriented polydisperse spheroids, J. Geophys. Res.-Atmos., 102, 16831-16847, 1997.

Mogili, P. K., Yang, K. H., Young, M. A., Kleiber, P. D., and Grassian, V. H.: Environmental aerosol chamber studies of extinction spectra of mineral dust aerosol components: Broadband IRUV extinction spectra, J. Geophys. Res.-Atmos., 112, D21204, doi:10.1029/2007JD008890, 2007.

Moore, D. M. and Reynolds, R. C. J.: X-Ray Diffraction and the Identification and Analysis of Clay Minerals, Oxford University Press, Oxford, New York, 1997.

Müller, D., Weinzierl, B., Petzold, A., Kandler, K., Ansmann, A., Müller, T., Tesche, M., Freudenthaler, V., Esselborn, M., Heese, B., Althausen, D., Schladitz, A., Otto, S., and Knippertz, P.: Mineral dust observed with AERONET Sun photometer, Raman lidar, and in situ instruments during SAMUM 2006: Shapeindependent particle properties, J. Geophys. Res.-Atmos., 115, D07202, doi:10.1029/2009JD012520, 2010.

Müller, T., Schladitz, A., Massling, A., Kaaden, N., Kandler, K., and Wiedensohler, A.: Spectral absorption coefficients and imaginary parts of refractive indices of Saharan dust during SAMUM1, Tellus B, 61, 79-95, 2009.

Müller, T., Schladitz, A., Kandler, K., and Wiedensohler, A.: Spectral particle absorption coefficients, single scattering albedos, and imaginary parts of refractive indices from ground based insitu measurements at Cape Verde Island during SAMUM-2, Tellus B, 63, 573-588, 2011.

Otto, S., Bierwirth, E., Weinzierl, B., Kandler, K., Esselborn, M., Tesche, M., Schladitz, A., Wendisch, M., and Trautmann, T.: Solar radiative effects of a Saharan dust plume observed during SAMUM assuming spheroidal model particles, Tellus B, 61, 270296, 2009.

Petzold, A., Rasp, K., Weinzierl, B., Esselborn, M., Hamburger, T., Dornbrack, A., Kandler, K., Schutz, L., Knippertz, P., Fiebig, M., and Virkkula, A.: Saharan dust absorption and refractive index from aircraft-based observations during SAMUM 2006, Tellus B, 61, 118-130, 2009.
Press, W. H., Teukolsky, S. A., Vetterling, W. T., and Flannery, B. P.: Numerical Recipes in C: The Art of Scientific Computing, Cambridge University Press, Cambridge, 1992.

Querry, M. R.: Optical constants of minerals and other materials from the millimeter to the UV, Rep. CRDEC-CR-88009, US Army, Aberdeen, MD, 1987.

Reid, J. S., Jonsson, H. H., Maring, H. B., Smirnov, A., Savoie, D. L., Cliff, S. S., Reid, E. A., Livingston, J. M., Meier, M. M., Dubovik, O., and Tsay, S. C.: Comparison of size and morphological measurements of coarse mode dust particles from Africa, J. Geophys. Res.-Atmos., 108, 8593, doi:10.1029/2002JD002485, 2003.

Scheuvens, D., Kandler, K., Küpper, M., Lieke, K., Zorn, S., Ebert, M., Schütz, L., and Weinbruch, S.: Indiviual-particle analysis of airborne dust samples collected over Morocco in 2006 during SAMUM 1, Tellus B, 63, 512-530, 2011.

Schladitz, A., Müller, T., Kaaden, N., Massling, A., Kandler, K., Ebert, M., Weinbruch, S., Deutscher, C., and Wiedensohler, A.: In situ measurements of optical properties at Tinfou (Morocco) during the Saharan Mineral Dust Experiment SAMUM 2006, Tellus B, 61, 64-78, 2009.

Schnaiter, M., Schmid, O., Petzold, A., Fritzsche, L., Klein, K. F., Andreae, M. O., Helas, G., Thielmann, A., Gimmler, M., Möhler, O., Linke, C., and Schurath, U.: Measurement of wavelengthresolved light absorption by aerosols utilizing a UV-VIS extinction cell, Aerosol Sci. Technol., 39, 249-260, 2005.

Sokolik, I., Andronova, A., and Johnson, T. C.: Complex Refractive-Index of Atmospheric Dust Aerosols, Atmos. Environ A-Gen., 27, 2495-2502, 1993.

Sokolik, I. N. and Toon, O. B.: Incorporation of mineralogical composition into models of the radiative properties of mineral aerosol from UV to IR wavelengths, J. Geophys. Res.-Atmos., 104, 9423-9444, 1999.

Wagner, R., Linke, C., Naumann, K. H., Schnaiter, M., Vragel, M., Gangl, M., and Horvath, H.: A review of optical measurements at the aerosol and cloud chamber AIDA, J. Quant. Spectrosc. Ra., 110, 930-949, 2009.

Wagner, R., Ajtai, T., Kandler, K., Lieke, K., Linke, C., Müller, T., Schnaiter, M., and Vragel, M.: Complex refractive indices of Saharan dust samples at visible and near UV wavelengths: a laboratory study, Atmos. Chem. Phys. Discuss., 11, 21363 21427, doi:10.5194/acpd-11-21363-2011, 2011.

Wiegner, M., Gasteiger, J., Kandler, K., Weinzierl, B., Rasp, K., Esselborn, M., Freudenthaler, V., Heese, B., Toledano, C., Tesche, M., and Althausen, D.: Numerical simulations of optical properties of Saharan dust aerosols with emphasis on lidar applications, Tellus B, 61, 180-194, 2009.

WMO: World Climate Program (WCP)/IAMAP, A preliminary cloudless standard atmosphere for radiation computation, WMO, Geneva, 1986.

Yang, P., Feng, Q., Hong, G., Kattawar, G. W., Wiscombe, W. J., Mishchenko, M. I., Dubovik, O., Laszlo, I., and Sokolik, I. N.: Modeling of the scattering and radiative properties of nonspherical dust-like aerosols, J. Aerosol Sci., 38, 995-1014, 2007.

Zakharova, N. T. and Mishchenko, M. I.: Scattering properties of needlelike and platelike ice spheroids with moderate size parameters, Appl. Optics, 39, 5052-5057, 2000. 